\title{
Mutations in the Insulator Protein Suppressor of Hairy Wing Induce Genome Instability
}

Shih-Jui Hsu ${ }^{1,2}$, Emily C. Stow ${ }^{1}$, James R. Simmons ${ }^{1}$, Heather A. Wallace ${ }^{1,3}$, Andrea Mancheno Lopez $^{1}$, Shannon Stroud ${ }^{1}$, and Mariano Labrador ${ }^{1 \dagger}$

Department of Biochemistry and Cellular and Molecular Biology, The University of Tennessee, Knoxville, TN 37996, USA

Authors affiliation:

${ }^{1}$ Department of Biochemistry and Cellular and Molecular Biology, The University of Tennessee, Knoxville, TN 37996, USA

${ }^{2}$ Current Address: Navican Genomics, Inc. 341 S. Main Street. Salt Lake City. UT 84111, USA

${ }^{3}$ Current Address: Broad Institute of MIT and Harvard University, Boston, Massachusetts 02115, USA

${ }^{\dagger}$ Author for correspondence (labrador@utk.edu)

Running title: Insulator proteins maintain genome integrity

Keywords: Chromatin insulators, chromatin boundaries, gypsy, suppressor of Hairy wing, $\mathrm{Su}(\mathrm{Hw})$, Drosophila, oogenesis, Gurken, ATR, ATR mediated DNA damage response, MTOC, Double strand breaks (DSBs), $\gamma \mathrm{H} 2 \mathrm{Av}, \mathrm{H} 4 \mathrm{~K} 20 \mathrm{me} 1$, Chk1, grapes, endoreplication, replication stress 


\section{Abstract}

Chromatin insulator proteins mediate the formation of contacts between distant insulator sites along chromatin fibers. Long-range contacts facilitate communication between regulatory sequences and gene promoters throughout the genome, allowing accurate gene transcription regulation during embryo development and cell differentiation. Lack of insulator function has detrimental effects often resulting in lethality. The Drosophila insulator protein Suppressor of Hairy wing $[\mathrm{Su}(\mathrm{Hw})]$ is not essential for viability, but plays a crucial role in female oogenesis. The mechanism(s) by which $\mathrm{Su}(\mathrm{Hw})$ promotes proper oogenesis remains unclear. To gain insight into the functional properties of chromatin insulators, we further characterize the oogenesis phenotypes of $s u(H w)$ mutant females. We find that mutant egg chambers frequently display an irregular number of nurse cells, have poorly formed microtubule organization centers (MTOC) in the germarium, and show mislocalized Gurken (Grk) in later stages of oogenesis. Furthermore, eggshells produced by partially rescued $s u(H w)$ mutant females exhibit dorsoventral patterning defects that are identical to defects found in spindle mutants or in piRNA pathway mutants. Further analysis reveals an excess of DNA damage in egg chambers, which is independent of activation of transposable elements, and that Gurken localization defects and oogenesis progression are partially rescued by mutations in $m e i-41$ and $c h k l$ genes. In addition, we show that $\mathrm{Su}(\mathrm{Hw})$ is required for chromosome integrity in dividing neuroblasts from larval brains. Together, these findings suggest that $\mathrm{Su}(\mathrm{Hw})$ plays a critical role in maintaining genome integrity during germline development in Drosophila females as well as in dividing somatic cells. 


\section{Introduction}

Chromatin insulators facilitate higher-order chromatin organization in the nucleus by stabilizing interactions between distant sites in the chromatin fiber. These long-range contacts help orchestrate interactions between regulatory sequences and gene promoters to accommodate the complex genomic networks of gene transcription required to promote cell and tissue differentiation during embryo development (Labrador and Corces, 2002; Lupianez et al., 2015; Yang and Corces, 2012). Insulator function is conserved throughout eukaryotes (Gurudatta and Corces, 2009; Heger and Wiehe, 2014; Schoborg and Labrador, 2014; Schoborg and Labrador, 2010; Van Bortle and Corces, 2012b). Canonical insulator properties include the ability to prevent communication between distal enhancers and promoters when positioned in between them and function as boundaries to protect genes against heterochromatin-mediated silencing (Brasset and Vaury, 2005; Gaszner and Felsenfeld, 2006; Kellum and Schedl, 1991; Roseman et al., 1993; Udvardy et al., 1985; West et al., 2002; Zhao et al., 1995). These properties are mediated by insulator proteins, which bind the insulator DNA and may facilitate long-range DNA-DNA interactions (Phillips-Cremins and Corces, 2013; Van Bortle and Corces, 2012a). Recent progress in the study of insulator protein distribution and in the analysis of the three-dimensional organization of the genome within the nucleus has revealed a role of these proteins in the architectural organization of the genome (Lieberman-Aiden et al., 2009; Negre et al., 2010; Ong and Corces, 2014; Phillips-Cremins and Corces, 2013; Rao et al., 2014; Rowley et al., 2017). Thus, a new paradigm has emerged where insulator proteins in combination with cohesin establish topologically associating domains of DNA, which 
correspond with topologically independent regions of gene transcription activation or repression throught the genome (Fudenberg et al., 2016; Smith et al., 2016). However, although the functional principles behind this organization are strongly supported by experimental ovservations in mammalian cells, the question of whether this model of genome organization is universal amongst euckayotes, as well as the implications of the model in genome organization, genome function and genome integrity, remain an active focus of research (Canela et al., 2017; Oomen et al., 2019; Rowley et al., 2017).

The gypsy retrotransposon found in Drosophila contains one of the earliest characterized insulators. Gypsy can integrate at sites between enhancers and promoters, thereby disrupting enhancerpromoter communication and causing mutations that can be suppressed by mutations in the suppressor of Hairy wing gene [su(Hw)] (Modolell et al., 1983; Parkhurst and Corces, 1986; Spana et al., 1988). In addition to $\mathrm{Su}(\mathrm{Hw})$, which directly binds to the insulator DNA, two other proteins are required for gypsy insulator function: Modifier of $\operatorname{mdg} 4[\operatorname{Mod}(\operatorname{mdg} 4)-67.2]$ and Centrosomal Protein 190 (CP190), which directly interact with Su(Hw) (Georgiev and Kozycina, 1996; Georgiev and Gerasimova, 1989; Ghosh et al., 2001; Pai et al., 2004). Unlike other insulator proteins in Drosophila such as dCTCF, CP190, BEAF, or GAGA factor, the function of both $\mathrm{Su}(\mathrm{Hw})$ and its binding partner Mod(mdg4)-67.2 are dispensable for viability (Butcher et al., 2004; Gerasimova et al., 1995; Katokhin et al., 2001; Klug et al., 1968; Mohan et al., 2007; Roy et al., 2007). CP190 has insulator activity that is independent from $\mathrm{Su}(\mathrm{Hw})$ and forms insulators in the genome in association with other insulator proteins (Bushey et al., 2009; Mohan et al., 2007; Moshkovich et al., 2011). Homozygous $s u(H w)$ loss-of-function mutations are viable with no evident phenotype other than female sterility (Klug et al., 1968; Klug et al., 1970). In ovaries, 
$\mathrm{Su}(\mathrm{Hw})$ is detected in the nucleus of both somatic follicle cells and germ cells (Baxley et al., 2011). Specifically, loss of $\mathrm{Su}(\mathrm{Hw})$ leads to suppression of yolk deposition in the oocyte and oocyte development is arrested at mid-oogenesis (Harrison et al., 1993; Klug et al., 1968; Klug et al., 1970). More recent findings have revealed that loss of $\mathrm{Su}(\mathrm{Hw})$ leads to an upregulation of neuronal gene expression in germline tissue, suggesting that missexpression of these genes could be responsible for the sterility phenotype of $s u(H w)$ mutations (Baxley et al., 2011; Harrison et al., 1993; Soshnev et al., 2013; Soshnev et al., 2012). In fact, the oogenesis phenotype in $s u(H w)$ mutant females can be partially suppressed by mutations that reduce the expression of the RNAbinding protein $9(\mathrm{Rbp} 9)$, a protein expressed at higher levels in $s u(H w)$ mutant ovaries that is involved in blood-brain barrier establishment (Kim et al., 2010; Soshnev et al., 2013). Rescued females, however, do not produce viable offspring, and eggshells from laid embryos reveal strong dorsoventral transformations. Given the complexity of this phenotype, analysis of $s u(H w)$ mutations in the female germ line could be instrumental for further understanding the role of $\mathrm{Su}(\mathrm{Hw})$ in oogenesis and the function of insulator proteins during development in general.

In Drosophila, oogenesis begins with the asymmetric cell division of a germline stem cell located at the tip of the germarium, which gives rise to a daughter stem cell and a cystoblast. The cystoblast undergoes four incomplete mitotic divisions, forming an egg chamber containing sixteen germ cells that remain interconnected and are enclosed by an epithelium of follicle cells. Only one of the sixteen germ cells will adopt the oocyte cell fate while the remaining fifteen cells become nurse cells. Each egg chamber undergoes a developmental process that culminates with the formation of a mature oocyte at stage 14 . As oogenesis progresses, at stage 6 , the nucleus of nurse cells undergoes a dramatic change from a condensed five-blobs chromosome 
configuration to a decondensed chromosome morphology (Bate and Martinez Arias, 1993; Dej and Spradling, 1999). Before mid-oogenesis arrest, the only visible chromatin-configuration defect in $s u(H w)$ mutant egg chambers is a delayed chromatin dispersal of nurse cell polytene chromosomes at stage 7 or 8 . The prolonged development of defective egg chambers is eliminated by mid-oogenesis arrest resulting in egg chamber degeneration around stages 9 to 10 (Baxley et al., 2011; Harrison et al., 1993; Klug et al., 1968). This defective chromatin dispersal is a common trait among a large number of unrelated mutants, such as genes encoding the splicesosome component prp22 (Klusza et al., 2013), the piwi-interacting RNAs (piRNAs) related protein, and rhino (Klattenhoff et al., 2009; Volpe et al., 2001), which complicates the identification of the mechanisms associated with $\mathrm{Su}(\mathrm{Hw})$ activity in the genome of egg chamber cells.

In addition to defects resulting from mutations in oogenesis genes, uncontrolled transposon activity may also cause a severe disruption of development during oogenesis. piRNAs are critical molecules involved in suppression of transposable element activity. These RNA sequences were originally called repeat-associated siRNAs (rasi-RNAs) as they are derived from repetitive sequences in the genome (Aravin et al., 2003; Brennecke et al., 2007; Feschotte, 2008; Yin and Lin, 2007). Mutations in genes involved in piRNA production such as aubergine $(a u b)$, spindle-E (spnE), and maelstrom (mael) result in transposable element overexpression and mobilization that create double strand breaks (DSBs) in the host genome (Chen et al., 2007; Cook et al., 2004; Klattenhoff et al., 2007; Sienski et al., 2012). The unleashed retrotransposon activation triggers the DNA damage response, causing defects in microtubule polarization in early oogenesis that further disrupt Gurken signaling in later stages that are essential for 
dorsoventral determination in embryonic development (Chen et al., 2007; Khurana and

Theurkauf, 2010; Klattenhoff et al., 2007). Interestingly, the DNA damage response resulting from over-activation of retrotransposons has been known to utilize the same pathway triggered by unrepaired DSBs in mutants of spindle class genes encoding meiotic DNA damage repair proteins. These unrepaired DSBs activate meiotic checkpoints mediated by mei-4l (ataxia telangiectasia-related- ATR-ortholog) and mnk (checkpoint kinase 2- chk2-ortholog) (Abdu et al., 2002; Ghabrial and Schupbach, 1999; LaRocque et al., 2007; Staeva-Vieira et al., 2003).

In this study, we conclude that the loss of $\mathrm{Su}(\mathrm{Hw})$ creates an accumulation of nonmeiotic DNA damage in germline cells of ovaries, thereby activating DNA damage checkpoints. We show that DNA damage is independent of transposable element activity and that mutations in meiotic checkpoint genes mei-41 (ATR) and grapes (chkl), but not mnk (chk2, loki), result in the rescue of the $s u(H w)$ mutant spindle phenotype in ovaries. We conclude that the lack of $s u(H w)$ expression in ovaries provokes an excess of unrepaired DNA breaks in germline cells, and propose that this DNA damage is caused by replication stress. Our data supports that replication stress occurs in dividing somatic cells as well, in $s u(H w$ mutants.

\section{Results}

Egg chambers from $s u(H w)$ mutant ovaries exhibit an irregular number of nurse cells: Loss of $\mathrm{Su}(\mathrm{Hw})$ causes incomplete oocyte development, resulting in egg chamber degeneration at mid-oogenesis (Baxley et al., 2011; Harrison et al., 1993; Klug et al., 1968; Klug et al., 1970). Previous observations identified an increased number of nurse cells in a fraction of egg chambers from homozygous $s u(H w)^{v}$ and $s u(H w)^{e 04061 / 2}$ trans-heterozygous mutants, but this phenotype was 
not considered a true $s u(H w)$ mutant phenotype (Baxley et al., 2011; Harrison et al., 1993). To further examine the function of $\mathrm{Su}(\mathrm{Hw})$ in oogenesis, we performed a comprehensive analysis of the causes of female sterility in $s u(H w)$ mutants including an evaluation of the aberrant nurse cell number phenotype. We used the $s u(H w)^{e 04061}$ mutant allele containing an insertion of a piggyBac transposon in the 5' end of the second exon of $s u(H w)$ (Baxley et al., 2011; Schoborg et al., 2013) as well as $s u(H w)^{v}$, which carries a deletion of the $s u(H w)$ promoter (Harrison et al., 1992). We observed an abnormal number of nurse cells in mutant egg chambers from both homozygous $s u(H w)^{e 04061}$ and trans-heterozygous $s u(H w)^{v / e 04061}$ mutants (Figure 1B-D). Therefore, we quantified the number of nurse cells per individual egg chamber in $s u(H w)^{v / e 04061}$ transheterozygous mutants using an antibody against lamin to stain the nuclear periphery of nurse cells. Mutant and wildtype stained ovaries were selected randomly, and egg chambers were analyzed using maximum projections of 20 Z-stack images that were collected with increments of $2 \mu \mathrm{m}$.

Results show that in addition to egg chambers with an increased number of nurse cells, some trans-heterozygous $s u(H w)^{v / e 04061}$ egg chambers also have a reduced number of nurse cells. Overall, $7.48 \%$ of the $s u(H w)^{v / e 04061}$ mutant population of egg chambers had an irregular number of nurse cells. Approximately $2 \%$ of egg chambers had more than fifteen nurse cells (Figure 1 E). This phenotype may arise from defective development of follicle cells, which may lead to fused chambers (Mata et al., 2000). Alternatively, this phenotype may result from additional mitotic divisions of cystoblasts occurring in the early germarium. Interestingly, $5.61 \%$ of egg chambers were found to have a reduced number of nurse cells, a phenotype that may indicate incomplete mitotic divisions in the germarium stage. This reduced nurse cell number phenotype 
upon loss of $\mathrm{Su}(\mathrm{Hw})$ was previously unreported and overall, the irregular nurse cell number in $s u(H w)$ mutant ovaries compared with wildtype is statistically significant $(\mathrm{p}<0.05$, Fisher's exact test). Counting the number of ring canals connecting nurse cells with the oocyte provides an indication of whether egg chambers with an irregular nurse cell number originate from incomplete cell divisions, extra cell divisions, or by egg chamber fusions (Wang et al., 2010). After counting the number of ring canals contacting the oocyte in egg chambers with less than 15 nurse cells, we found that $33 \%$ contained less than 4 rings, suggesting incomplete nurse cell divisions. In $67 \%$ of egg chambers with less than 15 nurse cells, the number of rings was 4 , suggesting cell death may have occurred in these chambers. Finally, supernumerary egg chambers always have more than 4 ring canals in their oocyte, suggesting these chambers had extra cell divisions (Figure S1).

To confirm that this phenotype is caused by the lack of $\mathrm{Su}(\mathrm{Hw})$ in the germline, we quantified nurse cell number in $s u(H w)^{v / e 04061}$ trans-heterozygous females expressing a $\mathrm{Su}(\mathrm{Hw}): e G F P$ transgene in the germline driven by a nanos-GALA driver (P $\{$ nos-GAL4::VP16\}). The nanos-GAL4 driver directs the expression of GAL4 throughout all the stages of oogenesis (Rorth, 1998; Van Doren et al., 1998). We have previously shown that $s u(H w):: e G F P$ completely rescues insulator activity in $s u(H w)$ mutants (Schoborg et al., 2013) and partially rescues the fertility of these mutants when expressed in the germline (Hsu et al., 2015). Our results show that all 65 egg chambers analyzed in ovaries from females expressing the rescue construct contain the expected number of 15 nurse cells (Figure $1 \mathrm{E}$ ). Taken together, these observations suggest that loss of $s u(H w)$ causes an irregular number of nurse cells. 
Microtubules are disorganized in $s u(H w)$ mutant egg chambers: Abnormal nurse cell number in egg chambers occurs in loss of function mutants of genes encoding proteins involved in piRNA-related pathways, including rihno and maelstrom (mael) (Sato et al., 2011; Volpe et al., 2001). mael encodes a $\gamma$-tubulin associated protein involved in the proper positioning of the MTOC, which is required to determine oocyte polarity and the precise localization of specific mRNAs within the Drosophila oocyte (Clegg et al., 2001; Clegg et al., 1997; Sato et al., 2011). Microtubule organization is critical at various stages of oogenesis. In stage one, formation of the MTOC, a structure with concentrated $\alpha$-tubulin at the posterior of the oocytes, is required for oocyte differentiation. In stages 3 through 6 , a microtubule array is extended from the MTOC through ring canals to the neighboring nurse cells. This polarized network of microtubules is required for intercellular transport from nurse cells to the oocyte. During stage 7 the microtubule network is reorganized, causing a shift in the polarity of the MTOC from posterior to anterior, and the growing microtubule network positions the oocyte nucleus to the anterior corner (Steinhauer and Kalderon, 2006; Theurkauf et al., 1992).

To assess whether $\mathrm{su}(\mathrm{Hw})$ mutants also show microtubule disorganization in addition to an irregular number of nurse cells, we used an anti $\alpha$-tubulin antibody that allows detection of microtubule networks in egg chambers (Theurkauf et al., 1992). We found that, under our experimental conditions, MTOCs form properly in wildtype ovaries, exhibiting the typical concentration of $\alpha$-tubulin at the posterior of the oocyte in the germarium (Figure $2 \mathrm{C}$ and $\mathrm{G}$ ). However, in $s u(H w)$ mutants, the $\alpha$-tubulin signal is weaker, more diffuse, and less concentrated at the MTOC (Figure $2 \mathrm{~A}$ and $\mathrm{E}$ ). This phenotype was specific to $s u(H w)$ mutants, as we did not observe the same phenotype in the $\bmod (\operatorname{mdg} 4)^{u l}$ mutant (Figure $2 \mathrm{~B}$ and F). 
Additionally, we were able to rescue the MTOC defect in the germarium of $s u(H w)$ mutant ovarioles by ectopic expression of $s u(H w):: e G F P$ driven by the nanos-GAL4 driver (Figure $2 \mathrm{D}$ and $\mathrm{H}$ ). These data suggest that proper formation of the MTOC is impaired upon loss of $\mathrm{Su}(\mathrm{Hw})$ and imply that the microtubule network is disorganized and may not function efficiently to facilitate egg chamber development. For example, it is well established that defects in MTOC regulation that affect establishment of polarity in early oogenesis result in the disruption of Grk signaling in later stages of oogenesis (Khurana and Theurkauf, 2010).

Gurken is mislocalized in the oocyte of $s u(H w)$ mutant egg chambers: Embryo dorsoventral patterning is determined by the key axis-determining mRNAs of gurken (grk), oskar (osk), and bicoid $(b c d)$, which are transported along microtubules to specific locations within the oocyte (Kugler and Lasko, 2009). To test whether defective microtubule organization in $s u(H w)$ mutants could also affect axis determination, we used anti-Grk antibodies to detect the localization of Grk, a Drosophila transforming growth factor $\alpha$ (TGF $\alpha$ ) protein, which is important for dorsoventral determination of embryos (Neuman-Silberberg and Schupbach, 1993). grk mRNA requires transportation to the oocyte prior to translation, and Grk protein specifically localizes at the posterior of the oocyte during stage 6 (Figure $3 \mathrm{~A}$ and $\mathrm{B}$ ).

Later, as the oocyte relocates to the anterior-dorsal corner, Grk gradually moves to the corner and forms a crescent shape around the oocyte nucleus at stage 9 (Figure 3 C). Our data shows that in $s u(H w)$ mutants, Grk fails to translocate to the anterior-dorsal corner of the oocyte in $95 \%(\mathrm{~N}=20)$ of the egg chambers at stage 9 , compared with $100 \%$ correct localization in 
wildtype $(\mathrm{N}=16)(\mathrm{p}<0.001$, Fisher's exact test) (Figure 6). Mislocalization of Grk normally leads to failure of the oocyte to signal follicle cells to determine dorsal fate, consequently interrupting the axis plan of the developing egg chamber. Our data suggest that loss of $\mathrm{Su}(\mathrm{Hw})$ causes defective formation of the microtubule network in developing egg chambers and the subsequent mislocalization of Grk.

\section{Non-meiotic DNA damage occurs during oogenesis in $s u(H w)$ mutants: Disorganized}

microtubules and mislocalized Grk are oogenesis phenotypes observed in mutants of the spindle class genes (Ghabrial et al., 1998) and the piRNA pathway (Chen et al., 2007; Klattenhoff et al., 2007; Sato et al., 2011). In these mutants, cells lose the ability to repair DNA damage or to repress retrotransposon activity, generating an excess of DNA double-strand breaks (DSBs) such that unrepaired DSBs activate the ATR/Chk2 dependent DNA-damage signaling pathway in the female germline (Khurana and Theurkauf, 2010). Therefore, our results suggest that DNA damage signaling pathways are activated in $s u(H w)$ mutants, resulting in disorganization of the MTOC and Grk mislocalization in the oocyte.

In order to further investigate whether the ATR-mediated DNA damage pathway is activated by DNA damage in $s u(H w)$ mutants, we performed immunostaining in ovaries using antibodies against phosphorylated Histone $2 \mathrm{~A}$ variant $(\gamma \mathrm{H} 2 \mathrm{Av})$, a marker for DNA damage. In Drosophila oocytes, DNA damage can be produced by three major sources: DNA damage induced by transposable element activity, DNA damage induced by replication stress, and meiotic DSB induced by Spo11, a nuclease required for meiotic recombination encoded by the mei-w68 gene in Drosophila. These meiotic DSBs are normally repaired before developing egg 
chambers reach stage one (Jang et al., 2003; McKim and Hayashi-Hagihara, 1998; Mehrotra and McKim, 2006).

To characterize whether the loss of $s u(H w)$ induces DNA damage and whether the DNA damage is associated with the meiotic recombination pathway, we used $\gamma \mathrm{H} 2 \mathrm{Av}$ to compare the DNA damage in wildtype, $s u(H w)$ mutants, mei-w68 mutants, and mei-w68; su(Hw) double mutants. In wildtype germaria, we observed naturally occurring DNA damage in dividing cystocytes (which later become nurse cells and pro-oocytes) in region 2, where homologous recombination takes place (Figure $4 \mathrm{~A}$ and $\mathrm{B}$ ). As expected, mei-w68 (Spo11) homozygous mutants showed no DSBs in region 2 of the germarium, indicating a lack of Spo11 activity and the absence of other significant factors inducing DNA damage. Remarkably, we found an excess of non-meiotic DSBs in region 2 nurse cells from the germarium of $s u(H w)$ and mei-w68 double mutants, demonstrating that DNA damage in $s u(H w)$ mutants is not produced by Spo11, and is therefore of non-meiotic origin (Figure 4 B and D). Additionally, we observed that in wildtype ovaries, $\gamma \mathrm{H} 2 \mathrm{Av}$ signal is absent after stage 5, as described in an earlier study (Joyce et al., 2011). Interestingly, the $\gamma \mathrm{H} 2 \mathrm{Av}$ signal remains present until later stages in $s u(H w)$ mutant egg chambers (Figure $4 \mathrm{I}$ and $\mathrm{J})$. This result strongly indicates that loss of $\mathrm{Su}(\mathrm{Hw})$ leads to formation and accumulation of non-meiotic DNA damage in female germline cells.

\section{$\mathrm{Su}(\mathrm{Hw})$ does not play a major role in regulating global transposable element activity in the}

Drosophila germline: $\mathrm{Su}(\mathrm{Hw})$ strongly regulates transcription of the gypsy retrotransposon, and loss of the insulator activity reverses the phenotype of gypsy induced mutations at several loci in Drosophila (Harrison et al., 1993; Parkhurst and Corces, 1985; Parkhurst and Corces, 1986; 
Parkhurst et al., 1988). Additionally, global activation of transposable elements (TEs) in the germline triggers the activation DNA damage checkpoints most likely due to an excess of DNA damage, producing phenotypes similar to those described here (Chen et al., 2007; Khurana and Theurkauf, 2010; Klattenhoff et al., 2007; Mohn et al., 2014). Our data demonstrating the accumulation of non-meiotic DNA damage in female germline cells of $s u(H w)$ mutants led us to ask whether TEs are over-expressed in the germline of these mutants.

We performed real-time RT-PCR to quantify the transcripts of TEs produced in wildtype and $s u(H w)^{e 04061}$ homozygous mutant ovaries. In both genotypes, egg chambers stage 9 and older were removed manually to eliminate differences in expression levels that could originate from differences in developmental stages between the two samples. Total RNA extracted from mutant and wildtype ovaries was used for real-time RT-PCR. We used 17 primer sets specifically designed to determine the expression of 17 different TEs. Additionally, we used primers for $r p 49$ as an internal control. Our selection of TEs includes germline and somatic specific transposons and covers TEs with long-terminal repeats (LTR) as well as non-LTR elements.

The expression levels of 17 TEs in mutant ovaries were compared to wildtype in a foldchange graph (Figure 5). Consistent with previous studies, our data show that the transcription levels of gypsy as well as stalker4 are reduced significantly in $s u(H w)$ mutants. Compared with the transcription levels of TEs in spindle mutants, which can reach levels of more than 100-fold increase, and considering that the majority of TEs tested showed no significant change in transcription levels, it seems unlikely that TEs are the cause of significant DNA damage in $s u(H w)$ mutants. 


\section{Loss of $\mathrm{Su}(\mathrm{Hw})$ activates a DNA damage checkpoint during oogenesis: Because of the} similarity between spindle class and piRNA mutants with $s u(H w)$ mutant phenotypes and the elevated levels of $\gamma \mathrm{H} 2 \mathrm{Av}$ seen in $s u(H w)$ mutant egg chambers, we hypothesize that $s u(H w)$ mutations activate a DNA damage checkpoint during oogenesis. We first tested whether $s u(H w)$ mutants activate a DNA damage signaling pathway by asking whether oocyte development is restored in females double mutant for $s u(H w)^{v / e 04061}$ and the Drosophila ATR allele, mei-41 ${ }^{D 5}$ (Brodsky et al., 2004; Laurencon et al., 2003). Results show that although double mutant females remained sterile, $54 \%$ of egg chambers recovered correct positioning of Grk around the oocyte nucleus at stage nine, $(\mathrm{N}=24, \mathrm{p}<0.001$, Fisher exact test $)$, and had proper enlargement of the developing oocyte in stage nine and ten (Figure $6 \mathrm{C}, \mathrm{H}$, and I). These results show that loss of ATR function partially recovers oocyte development in $s u(H w)^{v / e 04061}$ mutants and suggests that loss of $\mathrm{Su}(\mathrm{Hw})$ function triggers a DNA-damage response through an ATR-dependent pathway.

Chk1 (Grp) and Chk2 (Mnk, Lok), two highly conserved downstream kinases in ATR/ATM DNA damage signaling, are both phosphorylated in response to DNA damage and participate in cell cycle checkpoint activation (Cimprich and Cortez, 2008). However, mutations of $\operatorname{chk} 2$, but not $\operatorname{chk} 1$, recover the dorsoventral patterning defects associated with mutants of spindle and piRNA pathway genes (Chen et al., 2007; Ghabrial et al., 1998; Klattenhoff et al., 2007). To determine the role of DNA repair pathways in $s u(\mathrm{Hw})$ mutant ovaries, we first tested the ability of $\operatorname{chkl}\left(\operatorname{grp}^{z 5170 / 209}\right) \operatorname{chk} 2\left(l o k^{30}\right)$ double mutant flies to rescue the mutant phenotypes of $s u(H w)^{v / e 04061}$ ovaries. We found that $\operatorname{grp}^{z 5170 / 209} \operatorname{lok}^{30}$ double mutants were able to rescue defective Grk localization, but were unable to rescue the lack of fertility in $s u(H w)$ mutants 
(Figure $6 \mathrm{D})$. To test whether the loss of $\mathrm{Su}(\mathrm{Hw})$ activates a DNA damage response specifically mediated by ATR/Chk2, we generated double mutant flies using $s u(H w)^{v / e 04061}$ and $\operatorname{chk} 2\left(\operatorname{lok}^{30}\right.$, $m n k^{6006}$ ) mutations (Brodsky et al., 2004) and tested whether a mutation in chk2 is able to rescue Grk localization in $s u(H w)$ mutants. The results showed that neither fertility nor Grk localization were rescued in these double mutants (Figure $6 \mathrm{E}$ and F). Finally, we generated double mutant flies using $s u(H w)^{v / e 04061}$ and $\operatorname{chkl}\left(\operatorname{grp}^{z 5170 / 209}\right)$ mutations. $g r p^{z 5170 / 209} ; s u(H w)^{v / e 04061}$ double mutants were able to rescue the Grk localization phenotype in $80 \%$ of egg chambers analyzed, but were unable to rescue the sterility phenotype (Figure $6 \mathrm{G}$ and I). These findings show that the spindle-like phenotypes caused by loss of $\mathrm{Su}(\mathrm{Hw})$ are dependent on Chk1 (grapes) mediated checkpoint activity, downstream of the ATR mediated DNA-damage pathway, and are independent of Chk2 (mnk, lok). Since ATR/Chk1 activate a checkpoint in response to replication stress (Blythe and Wieschaus, 2015; Fogarty et al., 1997; Sibon et al., 1997), our results suggest that mutations of $s u(H w)$ cause replication stress in developing egg chambers.

\section{Misexpression of $\mathrm{Su}(\mathrm{Hw})$ in mutant ovaries causes dorsoventral defects in eggshells: Our}

results have revealed that $\mathrm{Su}(\mathrm{Hw})$ may have a role in maintaining genome integrity by preventing replication stress in nurse cells. Accordingly, loss of $\mathrm{Su}(\mathrm{Hw})$ causes a significant increase in DNA damage, followed by defects in microtubule organization, egg chamber formation, and mislocalization of Grk. These phenotypes can be rescued by $m e i-41^{D 5}$ and $\operatorname{grp}^{z 5170 / 209}$, mutant alleles of ATR and Chk1 respectively, suggesting that the defects originate from the activation of checkpoints in response to DNA damage. 
In addition to these phenotypes, homozygous mutant females for spindle class genes produce embryos with dorsoventral defects in their eggshells which result from mislocalization of Grk and other morphogens in the developing oocyte (Ghabrial et al., 1998; Ghabrial and Schupbach, 1999). Egg chamber development in $s u(H w)$ mutants is arrested at mid-oogenesis, preventing the opportunity to test eggshells for the formation of dorsoventral defects. Interestingly, we have shown that $s u(H w):: e G F P$ expression driven by nanos-GAL4 (P $\{$ nanosGAL4::VP16\}) not only can rescue MTOC in egg chambers, (Figure 2) but also partially restores fertility in mutant flies. These rescued females laid a reduced number of eggs $(\sim 41 \%$ of normal females) (Hsu et al., 2015), and only less than $25 \%$ of these embryos produced viable adults, indicating that the spatio-temporal expression of nanos-GAL4; $s u(H w):: e G F P$ is not sufficient to fully restore $\mathrm{Su}(\mathrm{Hw})$ activity in all egg chambers from mutant ovaries.

Eggshells produced by nanos-GAL4; $s u(H w):: e G F P$ partially rescued females provide an opportunity to test whether loss of $\mathrm{Su}(\mathrm{Hw})$ also induces the formation of dorsoventral defects. We performed a quantitative analysis of the eggshell morphology produced by nanos-GAL4; $s u(H w):: e G F P$ females. Results show that all embryos that failed to develop displayed eggshells with dorsoventral axis defects (Figure 7A). We categorized these phenotypes as previously described in (Ghabrial et al., 1998): Type I: eggshells with two wildtype appendages, Type II: eggshells showing two short appendages, Type III: eggshells showing a single appendage, and Type IV: eggshells with no appendages. The number of each type of eggshell is shown in Figure 7B. Type I eggshells are only found in viable embryos and have no noticeable developmental defects through adult stage. These results show that in a large number of egg chambers expressing $s u(H w):: e G F P$ driven by nanos-GAL4, oogenesis defects are only partially rescued, 
and suggest that these chambers activate a spindle-like checkpoint that leads to dorsoventral transformations.

Surprisingly, it has been recently shown that heterozygous mutations in the Rbp 9 gene $\left(\operatorname{Rbp} 9^{P 2775 /+}, s u(H w)^{2 / v}\right)$ are able to rescue the sterility of $s u(H w)$ mutant females (Soshnev et al., 2013). However, embryos produced by these females show dorsoventral transformations in their eggshells. Soshnev and collaborators conclude that transformations are produced because of the lack of $\mathrm{Su}(\mathrm{Hw})$ expression in follicle cells, suggesting that expression of $\mathrm{Su}(\mathrm{Hw})$ in follicle cells is necessary to allow establishment of communication between Gurken and follicle cell receptors. In experiments described here, we used a nanos-GALA driver to express $\mathrm{Su}(\mathrm{Hw})$ in nurse cells. This driver induces transgene expression exclusively in the germline, showing expression peaks at the germarium and at stage 9, but does not activate expression in follicle cells (Rorth, 1998; Van Doren et al., 1998). We tested expression of $\mathrm{Su}(\mathrm{Hw}):$ :eGFP in follicle cells using antibodies against GFP, showing no detectable expression, yet $20 \%$ of the embryos were able to develop into normal adult flies, suggesting that expression of $s u(H w)$ is not required in follicle cells to support correct dorsoventral patterning during oogenesis (Hsu et al., 2015). Additionally, we found that the source of ventralized phenotypes in nanos-GAL4; $s u(H w):: e G F P$ eggshells can be attributed to mislocalization of Grk, since $29 \%$ of egg chambers from ovaries of these females also show mislocalization of Grk (Figure 7C and D).

We also generated nos-GAL4, $\mathrm{Su}(\mathrm{Hw}):: e G F P$ flies, in which the driver is $\mathrm{P}\{G A L 4-$ nos.NGT 40 ), that highly express $\mathrm{Su}(\mathrm{Hw}):: e G F P$ through oogenesis. In these flies, the sterility phenotype of $s u(H w)$ mutant females was poorly rescued, but a large number of egg chambers 
achieved normal oocyte enlargement and were able to reach the latest stages of oogenesis. nos$G A L 4, \mathrm{Su}(\mathrm{Hw}):: e G F P ; s u(H w)^{v / e 04061}$ flies laid $6.1 \%$ of expected eggs, compared to wildtype (Hsu et al., 2015). Nanos-GAL4::VP16 includes the nos 5' and 3' UTRs translation regulation sequences and appears to be a stronger driver than GAL4-nos.NGT, which includes a 3'UTR region from a tubulin mRNA (Tracey et al., 2000). Embryos from nos-GAL4, $\mathrm{Su}(\mathrm{Hw}):: e G F P$ females never developed into larvae and all eggshells showed ventralization phenotypes with the more severe classes more frequently represented than in embryos from nanos-GAL4::VP16 driver (Figure 7B). Importantly, the severity of the ventralization phenotypes correlates with a higher frequency of mislocalization of Grk (82\%) (Figure 7C and E), suggesting that defects stem from misexpression of $\mathrm{Su}(\mathrm{Hw})$ in oocytes and not from the lack of $s u(H w)$ expression in follicle cells. Altogether, this data further supports our findings that expression of $s u(H w)$ is required for genome stability during oogenesis and that loss of $\mathrm{Su}(\mathrm{Hw})$ results in the generation of DNA damage, followed by the activation of cell cycle checkpoints, mislocalization of Gurken, and dorsoventral patterning defects in eggshells.

Monomethylated H4K20 and $\gamma \mathrm{H} 2 \mathrm{Av}$ accumulate in $s u(H w)$ mutant ovaries: We have shown that loss of $\mathrm{Su}(\mathrm{Hw})$ causes an accumulation of DNA damage in nurse cells, but its origin remains uncertain since the damage is not derived from meiotic recombination and a substantial activation of TEs was not observed in these mutants. Given that, in addition to Spo11 and TE activity, a major contributing source of intrinsically produced DNA damage under normal conditions is replication stress (Zeman and Cimprich, 2014) and, because the spindle-like phenotype we observed is ATR/Chk1 dependent, we used monomethylated Histone 4 at lysine 20 (H4K20me1) as a marker to further test whether DNA damage in ovaries from $s u(H w)$ female 
mutants is related to irregularities in replication. H4K20me1 has an important role in maintaining genome stability (Beck et al., 2012b; Jorgensen et al., 2013; Wu and Rice, 2011).

Monomethylation of H4K20 is mediated by the PR-Set7/ SET8 methyltransferase, and removal of PR-Set7 results in DNA damage and S phase arrest (Jorgensen et al., 2007). Conversely, constant expression of PR-Set7 causes accumulation of H4K20me1 at replication origins and results in replication stress due to re-replication (Jorgensen et al., 2007; Tardat et al., 2010b). In Drosophila S2 cells, depletion of PR-Set7 affects chromosome compaction and higher-order chromatin organization, also triggering the DNA damage response (Sakaguchi et al., 2012; Sakaguchi and Steward, 2007). Additionally, highly proliferating tissues, such as wing discs and salivary glands, are smaller in size and contain fewer cells in pr-set7 mutants, due to improper cell division during development (Karachentsev et al., 2007; Karachentsev et al., 2005). Together, this evidence suggests that misregulation of H4K20me1 can alter chromatin organization and lead to genome instability in a manner dependent on the cell cycle and DNA replication.

We performed western blotting in ovaries using both anti- $\gamma \mathrm{H} 2 \mathrm{Av}$ and anti-H4K20me1 antibodies. Our results show that, as expected, the amount of $\gamma \mathrm{H} 2 \mathrm{Av}$ and the amount of H4K20me1 increased in $s u(H w)$ mutant ovaries compared to wildtype (Figure $8 \mathrm{~B})$. The increase in $\gamma \mathrm{H} 2 \mathrm{Av}$ levels revealed by western blots confirms our earlier observation that high levels of non-meiotic DNA damage occur in $s u(H w)$ mutant ovaries (Figure $8 \mathrm{~A})$. We also showed that an additional mutation in ATR $\left(m e i-41^{D 5}\right.$ ), which partially rescues oogenesis in $s u(H w)^{v / e 04061}$, does not significantly reduce the levels of $\gamma \mathrm{H} 2 \mathrm{Av}$ in mutant ovaries (Figure $8 \mathrm{~A}$ ), suggesting that $\mathrm{H} 2 \mathrm{Av}$ is likely phosphorylated also by ATM in $s u(H w)$ mutant ovaries. In addition, the elevated 
amounts of H4K20me1 in mutant ovaries support the notion that DNA damage may originate from replication stress, which we propose is caused by the loss of $\mathrm{Su}(\mathrm{Hw})$. Altogether, our results suggest that DNA damage in $s u(H w)$ mutants is caused by replication stress, which disrupts genome stability and eventually leads to checkpoint activation and contributes to the oogenesis phenotype of these mutants.

\section{Mutation of $\mathrm{su}(\mathrm{Hw})$ is associated with chromosomal aberrations in somatic tissues}

Results showing spindle like phenotypes in $s u(H w)$ mutant ovaries, and a partial rescue of this phenotype by mutations in mei-41 and grapes, suggest $\mathrm{Su}(\mathrm{Hw})$ may play a role in the maintenance of genome stability and that lack of $\mathrm{Su}(\mathrm{Hw})$ function may lead to replication stress. However, these data did not show whether $\mathrm{Su}(\mathrm{Hw})$ 's role in genome maintenance is general or if this role is specific to the female germline. To address this question, we obtained metaphase spreads from third instar larval neuroblasts mutant for $s u(H w)$, and chromosomes were scored for the presence of chromosomal aberrations (CABs). Dividing neuroblasts provide an ideal opportunity to score a large number of cells and have previously been used to quantify the occurrence of CABs (Gatti and Goldberg, 1991). Screening larval brains from homozygous $s u(H w)^{e 04061}$ larvae reveals neuroblasts with either normal karyotypes (Figure 9, A1) or karyotypes showing CABs (Figure 9, A2-6). Different types of aberrations were noted in this genetic background, including many with chromatid or isochromatid deletions. Numerous cells of this genotype carried more than one aberration (Figure 9, A4), with some genomes appearing largely fragmented (Figure 9, A5-6). The frequency of CAB occurrence per brain between genotypes was quantified over multiple brains, revealing a significant increase in the average ratio of cells per brain that contain CABs in the homozygous $s u(H w)^{e 04061}$ background $(11.9 \%$, 
Figure $9 \mathrm{~B}$ and $\mathrm{C})$ as compared to the wildtype strain Oregon $\mathrm{R}(\mathrm{OR})(\mathrm{p}=0.004)$. The frequency of CABs observed in OR is $0.7 \%$, close to previously reported values for wildtype CAB frequency (Mengoli et al., 2014; Merigliano et al., 2017), and is close in value to that obtained from the $s u(H w)^{e 04061} /$ TM6B heterozygote. Examination of brains from a trans-heterozygous $s u(H w)^{v / e 04061}$ genotype showed a similar increase in CAB frequency over OR as the $s u(H w)^{e 04061}$ homozygote ( $\mathrm{p}=0.0298)$, implying that this phenotype is not due to second-site mutations in the $s u(H w)^{e 04061}$ genetic background. This suggests that $s u(H w)$ has a role in maintaining chromosome integrity and that half the wildtype dosage of $s u(H w)$ is sufficient to prevent chromosomal aberrations from occurring.

\section{Discussion}

This study has uncovered a novel role for $\mathrm{Su}(\mathrm{Hw})$ in the maintenance of genome stability. This conclusion is supported by data showing that a DNA damage response is activated in $s u(H w)$ mutant egg chambers as well as by the occurrence of chromosomal aberrations in dividing neuroblasts from $s u(H w)$ mutant larval brains. Traditionally, gene mutations that lead to the activation of DNA damage response pathways in the germline of Drosophila females are recognized by the formation of dorsoventral patterning defects in eggshells (Abdu et al., 2002; Ghabrial et al., 1998). In $s u(H w)$ mutant ovaries, however, oogenesis arrests and oocytes do not fully develop, preventing direct observation of whether dorsoventral patterning defects in eggshells are an element of the phenotype. This, in combination with the circumstance that all other phenotypes associated with the production of elevated intrinsic DNA damage cannot be directly observed without the appropriate experimental analysis, may explain why the phenotype 
of $s u(H w)$ mutations has rarely been previously associated with DNA damage or the DNA damage response (Lankenau et al., 2000).

Here, we have shown that an irregular number of nurse cells, MTOC disorganization, and Grk mislocalization are defects in $s u(H w)$ mutant egg chambers. We also show that germline cells of $s u(H w)$ mutants undergo an excessive accumulation of $\mathrm{H} 2 \mathrm{Av}$ phosphorylation.

Furthermore, our data suggests that DNA damage activates an ATR mediated DNA response signaling pathway, which may activate checkpoints leading to a failure of MTOC formation and Grk mislocalization. The occurrence of these phenotypes also provides an explanation for our observation that females ectopically expressing $\mathrm{Su}(\mathrm{Hw})$ systematically produce eggshells with dorsoventral defects. These phenotypes are usually observed in mutants encoding DNA repair or piRNA pathway components (Figure 10) (Abdu et al., 2002; Chen et al., 2007; Ghabrial and Schupbach, 1999; Gonzalez-Reyes et al., 1997; Klattenhoff et al., 2007; Staeva-Vieira et al., 2003).

Ataxia Telangiectasia-Related (ATR) and Ataxia Telangiectasia-mutated (ATM) are two highly conserved kinases with central roles in DNA repair, cell-cycle checkpoint progression, and cell fate determination (Sancar et al., 2004). In the DNA damage response, ATM primarily acts in repair of DSBs, whereas ATR is activated in response to various DNA lesions, particularly those generated by replication stress (Zeman and Cimprich, 2014). Both kinases are able to phosphorylate unique downstream effectors as well as a number of common targets, such as the human $\mathrm{H} 2 \mathrm{AX}$ or the Drosophila equivalent $\mathrm{H} 2 \mathrm{Av}$. Phosphorylated $\mathrm{H} 2 \mathrm{AX}(\gamma \mathrm{H} 2 \mathrm{AX})$ in humans, or phosphorylated $\mathrm{H} 2 \mathrm{Av}(\gamma \mathrm{H} 2 \mathrm{Av})$ in Drosophila, is an indicator for ATR/ATM activity, and 
crosstalk between these two pathways occurs in response to DNA damage (Cimprich and Cortez, 2008; Sirbu and Cortez, 2013). Although the detailed mechanism of how ATR and ATM coordinately function during oogenesis in Drosophila is still unclear, it seems that both proteins have distinct functions. Specifically, ATM is primarily involved in DNA damage repair, whereas ATR is also involved in cell-cycle checkpoint regulation (Joyce et al., 2011).

Due to the fundamental role that $\gamma \mathrm{H} 2 \mathrm{AX}$ (or $\gamma \mathrm{H} 2 \mathrm{Av}$ ) has in all DNA damage repair pathways, the recognition of this modification has become a standard assay for DSB and DNA damage detection. In this study, we find a strong accumulation of $\gamma \mathrm{H} 2 \mathrm{Av}$ in mutant nurse cells, and reveal that mutation of the checkpoint gate keeper $A T R / m e i-41$ rescues the spindle-like phenotype in $s u(H w)$ mutants. Previous observations have shown that an elevated frequency of DSBs is generally produced by mutations in DNA repair genes or by retrotransposon activity induced by mutations in components of the pi-RNA pathway. Both phenomena can lead to DNA damage and the activation of checkpoint repair pathways mediated by ATR and Chk2, which are phenotypically characterized by microtubule disorganization and translational repression of Grk (Chen et al., 2007; Klattenhoff et al., 2007; Mohn et al., 2014; Sienski et al., 2012). Our data, however, shows that $s u(H w)$ mutant egg chambers display microtubule disorganization and Grk mislocalization, and that mutants for ATR and Chk1 (grp), but not Chk2 (mnk, lok), partially rescue this phenotype. This important difference suggests that an alternative pathway, mediated by ATR and Chk1 is activated by a response to accumulation of DNA damage in $s u(H w)$ mutant ovaries (Figure 10). This conclusion is further supported by our observation that DNA damage in $s u(H w)$ mutant ovaries results from a pathway independent from transposable element activity. 
A previous study reports that cutting the gene dosage of an RNA-binding protein, Rbp9, in half results in the rescue of female fertility in $s u(H w)^{2 / v}$ mutants (Soshnev et al., 2013). This study suggests that female sterility in $s u(H w)^{2 / v}$ mutants is due to the derepression of neuronal genes such as $\operatorname{rbp} 9$ in the germline that are under the transcriptional control of $\mathrm{Su}(\mathrm{Hw})$ binding sites. Our results support the idea that $\mathrm{Su}(\mathrm{Hw})$ has roles during oogenesis that extend beyond transcriptional regulation. One possibility against this notion is that $\mathrm{Su}(\mathrm{Hw})$ may control the expression of genes involved in DNA damage signaling in the ovaries. However, published reports show no indication that $\mathrm{Su}(\mathrm{Hw})$ specifically controls the expression of genes involved in DNA repair or replication pathways (Baxley et al., 2011; Hsu et al., 2015). Instead, we suggest that null mutations of $s u(H w)$ result in a complex multifactorial oogenesis phenotype. Sterility is caused mostly by the over-expression of neuronal genes such as $r b p 9$, due to the lack of transcriptional repression activity of $\mathrm{Su}(\mathrm{Hw})$, whereas the spindle-like phenotype described here would be dependent on the structural activity of $\mathrm{Su}(\mathrm{Hw})$ in the genome through its insulator function. Thus, a reduction of the levels of $\operatorname{rbp} 9$ is enough to restore oogenesis development but not sufficient to eliminate the ventralization phenotype induced by replication stress and the activation of the $A T R / \operatorname{chkl}$ checkpoint. Likewise, expression of $s u(H w):: e G F P$ driven by nanosGAL4 can partially rescue fertility but does not completely eliminate the spindle-like phenotype, producing frequent mislocalization of Grk and ventralized eggshells.

DNA breaks in $s u(H w)$ mutant females may be produced by two different mechanisms: an overall increase in the production of DNA breaks or a failure in the process of repairing DNA breaks. Intrinsic causes of DSBs in Drosophila female germline development are normally attributed to meiotic recombination, transposable element mobilization, or abnormal DNA 
replication. In this work, we have shown that excess of DNA damage in $s u(H w)$ mutant ovaries does not result from abnormal meiotic recombination (Figure 4), or retrotransposon mobilization (Figure 5), suggesting that accumulation of DNA damage may result from abnormal genome replication during oogenesis. In ovaries, endoreplication is a specialized genome replication process that takes place within a limited time during oogenesis and produces polyploid nurse cells that supply nutrients for oocyte development. Cells undergoing endoreplication only pass through a G phase and a S phase, but do not undergo mitosis (M) (Lee et al., 2009). Euchromatin is duplicated early during endoreplication while heterochromatic sequences are duplicated at late $\mathrm{S}$ phase. Because $\mathrm{S}$ phase is shorter in each endoreplication cycle, some heterochromatic regions frequently lose the opportunity for replication. This loss of replication is called underreplication, and damaged DNA has been observed at the junction between replicated euchromatin and underreplicated heterochromatin regions (Hammond and Laird, 1985; Lilly and Spradling, 1996b; Yarosh and Spradling, 2014). In salivary gland polytene chromosomes, for example, the accumulated $\gamma \mathrm{H} 2 \mathrm{Av}$ signals are detected at local underreplication sites (Andreyeva et al., 2008).

Because $\mathrm{Su}(\mathrm{Hw})$ has been associated with heterochromatin-euchromatin boundaries (Khoroshko et al., 2016), one possibility is that the absence of $\mathrm{Su}(\mathrm{Hw})$ in mutants disrupts the endoreplication process and leads to an excess of DNA damage at these sites. DNA breaks may result from stalled replication forks at the boundaries that fail to reinitiate replication (Lilly and Spradling, 1996a; Mirkin and Mirkin, 2007; Peng and Karpen, 2008). Interestingly, this mechanism has been suggested to explain the five lobes nuclear organization phenotype, which is typical in nurse cells during stages 1 to 5 of oogenesis, but that extends beyond stage 5 in $s u(H w)$ and in other oogenesis mutants (Dej and Spradling, 1999). The 5 lobes structure is the 
result of homolog chromosome pairing during re-replication, and in normal nurse cells, these chromosomes separate and disperse in the nucleus after stage 5. The 5 lobes anomalous phenotype at later stages results from failure of chromosomes to disperse, which is likely due to unfinished replication forks that prevent sister chromatids from dispersing after stage 5 (Dej and Spradling, 1999).

Whereas research on insulator proteins has focused mostly on their roles in transcription, the possibility that chromatin insulators might also be involved in genome replication emerged recently after analysis of the genomic distributions of insulators and origin of replication proteins. This analysis revealed that a number of ORC and MCM2-7 helicase complex binding sites overlap with binding sites of $\mathrm{Su}(\mathrm{Hw})$. In addition, $\mathrm{Su}(\mathrm{Hw})$ is also capable of altering chromatin accessibility by recruiting the histone acetyltransferase SAGA and the BRAHMA chromatin remodeling complex, thereby creating a platform of low nucleosome density levels favorable for the recruitment of ORC and replication firing (Lu and Tower, 1997; Vorobyeva et al., 2013). In line with these findings suggesting a role for $\mathrm{Su}(\mathrm{Hw})$ in the regulation of DNA replication, we have also found a significant accumulation of H4K20me1 in $s u(H w)$ mutant ovaries. H4K20me1 is highly regulated during the cell cycle and plays an important role in the licensing of origins of replication. PR-Set7 is the histone methyltransferase responsible for the monomethylation of H4K20 (H4K20me1). Mutations in PR-Set7 in mice models suggest that this protein has a role in DNA replication (Abbas et al., 2010; Tardat et al., 2010a). Specifically, mutations in set7 that prevent PR-Set7 degradation during the cell cycle are lethal due to uncontrolled re-replication of the genome (Centore et al., 2010), and loss of PR-Set7 enzymatic activity also causes defects in origin of replication firing (Jorgensen et al., 2007; Tardat et al., 
2007). Further experimental evidence has shown that the role of PR-Set7 in origins of replication depends on its specific mono-methyltransferase activity on H4K20. H4K20me1 functions as a substrate for subsequent methylation by Suv4-20h1 and Suv4-20h2 methyltransferases, which further dimethylate and trimethylate H4K20me1, respectively. H4K20me2 and H4K20me3 directly bind ORC and promote firing of replication forks at replication origins (Beck et al., 2012a).

Our finding showing increased levels of H4K20me1 in ovaries is reminiscent of mutations that prevent PR-Set7 degradation, increasing the frequency of H4K20me1 and leading to re-replication. The observation that Chk1, and not Chk2, is the kinase activated by ATR in response to replication stress, suggests that at least two checkpoint pathways (ATR/Chk1 and ATR/Chk2) can independently trigger microtubule disorganization and dorsoventral transformations (Figure 10). Convergence of the two pathways is most likely explained because of the functional role that DNA repair proteins, including ATR, Chk1, and Chk2, have in the MTOC, coordinating the cell cycle with DNA repair functions (Golan et al., 2010; Katsura et al., 2009; Shimada and Komatsu, 2009).

Altogether, our data suggest that DNA damage and genome instability may arise upon loss of $\mathrm{Su}(\mathrm{Hw})$ function in both germline and replicating somatic cells. Whether the DNA damage in $s u(H w)$ mutants results from defects in genome organization that lead to replication stress, defects in the DNA repair pathway, or both is still unknown. However, our observation of chromosomal aberrations in dividing neuroblasts in $s u(H w)$ mutants suggest this phenomenon expands also to replicating somatic cells and is not limited to the germline or to polytene 
chromosomes. Our study opens a new avenue to further understand the role of architectural proteins in genome function and genome stability.

\section{Materials and methods}

Fly genetics: All fly stocks were cultured on cornmeal-agar food with yeast at $25^{\circ} \mathrm{C}$. The fly stocks used in this study are: $y^{2} w c t^{6} ; s u(H w)^{v} / T M 6 B$, a gift from Victor Corces (Emory University); mei-41 ${ }^{D 5}$, and $\mathrm{w}^{*} ; \mathrm{P}\{$ GAL4-nos.NGT40\} (BDSC: 4442), which we refer to as nosGAL4 through the text, were gifts from Laura Lee (Vanderbilt University). $m e i-w 68$ and $\mathrm{P}\{$ nanos-GAL4::VP16\}, which we refer to as nanos-GAL4 throughout the text, were gifts from Bruce McKee (University of Tennessee). $m n k^{6006}$, was a gift from Bill Theurkauff (UMass Worcester). $g r p z^{5170} l o k^{30}$ and $g r p^{209} l o k^{30}$ lines were a gift from Eric Weischaus (Princeton University). We also used $\mathrm{Su}(\mathrm{Hw}):: e G F P\left[y w ; \mathrm{P}\left\{s u(H w):: e G F P, \mathrm{w}^{+}\right\}\right]$and $w^{1118} ; \mathrm{PBac}(\mathrm{RB}) s u(H w)^{e 04061} / \mathrm{TM} 6 \mathrm{~B}(\mathrm{BDSC}: 18224)$.

Immunofluorescence staining of ovaries: Three to five-day-old female ovaries were collected for ovary whole mount immunostaining as described previously (Page and Hawley, 2001). Briefly, tissues were fixed in 4\% paraformaldehyde in 1:1 PBS and heptane (Sigma) and washed with PBST. Fixed tissues were incubated with blocking solution. Primary antibodies used for staining were as follows: FITC-conjugated mouse anti-tubulin (Sigma, 1:500), mouse anti-C(3)G (from Scott Hawley, Stowers Institute for medical research), rabbit anti-eGFP (Invitrogen, 1:100), rabbit anti- $\gamma \mathrm{H} 2 \mathrm{Av}$ (Rockland, 1:5000), mouse anti-Orb, and anti-Grk (Developmental Studies Hybridoma Bank, 1:200). The following secondary antibodies were used at 1:200 
dilution: FITC-conjugated anti-rabbit IgG, TexasRed-conjugated anti-rabbit IgG, and FITCconjugated anti-mouse IgG (The Jackson Laboratory). F-actin staining was performed using Texas Red-X phalloidin (Life Technologies). Ovaries were stained with 4', 6-diamidino-2phenylindole (DAPI, $0.5 \mu \mathrm{g} / \mathrm{ml}$ ) and were mounted in Vectashield mounting medium (Vector Laboratories). Slides were analyzed under a Leica DM6000B wide-field fluorescence microscope equipped with a Hamamatsu ORCA-ER CCD camera and a HC PL FLUOTAR 20x/0.50NA objective. Image acquisition was performed using Simple PCI v6.6 (Hamamatsu Photonics). Images were processed using the AutoQuant 3D Deconvolution Algorithm utilizing an adaptive (blind) PSF implemented into Lecia Deblur (v2.3.2) software. Wildtype and mutant samples were prepared and imaged under identical conditions of immunostaining, microscope, camera, and software settings. Egg chamber stage was determined based on size (Sullivan et al., 2000) measured in FIJI (Schindelin et al., 2012).

Documentation of eggshell phenotype: Two- to three-day-old $s u(H w)$ mutant females carrying the $s u(H w):: e G F P$ transgenes driven by $\mathrm{P}\{G A L 4$-nos.NGT40 $\}$ or $\mathrm{P}\{$ nanos-GAL4::VP16 $\}$, were crossed to $y w$ male flies. Eggs were collected for three days using grape juice agar plates containing wet yeast paste (Sullivan et al., 2000). The eggshell morphology was observed and documented using a Leica MZ16FQ stereomicroscope equipped with a Leica DFC420 digital camera.

Western blot: Three to five-day-old female ovaries were dissected and homogenized in RIPA lysis buffer containing protease and phosphatase inhibitors (Roche). In some samples, stages 10 and older were removed manually under the dissecting microscope, previously to 
homogenization. After removal of stages 9 and older, wildtype and mutant ovaries contain the same developmental stages. Lysates were resolved on a $15 \%$ acrylamide gel, transferred overnight at $4^{\circ} \mathrm{C}$, and probed with anti- $\gamma \mathrm{H} 2 \mathrm{Av}$ (Rockland, 1:1000), rabbit anti-monomethylated H4K20 (Abcam, 1:1000) and mouse anti-lamin Dm0 (DSHB, 1:1000).

Real-time PCR: Real-time PCR quantification of TE expression was carried out with ABGene (Rockford, IL) SYBR green PCR master mix. PCR conditions for each primer pair were tested to determine the efficiency of amplification and to ensure that the amplification was in the linear range. PCR products for each primer pair were amplified from cDNA using the BioRad iQ5 Multicolor Real-Time PCR detection system (Primers listed in Supporting Information Table 1). cDNA was reverse transcribed from at least three different RNA samples. Threshold Cycle $(\mathrm{Ct})$ values were normalized to the $\mathrm{Ct}$ values of the housekeeping gene rp49. Change in expression level was calculated using the $\Delta \Delta \mathrm{Ct}$ method based on the $\mathrm{Ct}$ value for each PCR reaction (BioRad real-time PCR application guide). Results are presented as fold change in mutant relative to wildtype. The statistical significance of the results was calculated using Student's ttests.

\section{Chromosomal aberration (CAB) assay of larval brain squashes}

Wandering third instar larvae were quickly dissected in PBS to obtain the brain. Brains were incubated in a small volume of $0.5 \%$ sodium citrate, $\mathrm{pH} 6.00$, for 10 minutes. The brains were then fixed in 4\% paraformaldehyde (2:1:1 acetic acid, $16 \%$ paraformaldehyde, $\mathrm{dH}_{2} \mathrm{O}$ ) for 1 minute. The brains were squashed between a slide and a coverslip before staining with 4', 6diamidino-2-phenylindole (DAPI, $0.5 \mu \mathrm{g} / \mathrm{mL}$ ) and were mounted in Vectashield mounting 
medium (Vector Laboratories). To determine the frequency of metaphasic cells that show chromosomal aberrations (CABs) in larval brains, pictures were taken of approximately fifty fields of view per sample that contained at least one metaphasic cell. Microscopy was performed as described above. Micrographs of neuroblast karyotypes were examined using FIJI (Schindelin et al., 2012) and each metaphasic cell was scored manually for the presence of CABs based on DAPI staining. Comparisons between genotypes were performed using two-tailed Mann-Whitney t-tests.

\section{Acknowledgements}

We thank Dr. Laura Lee at Vanderbilt University for P\{GAL4-nos.NGT4O\} and mei-41 ${ }^{D 5}$ stocks, Dr. Victor Corces at Emory University for $y^{2} w c t^{6} ; s u(H w)^{v} / T M 6 B$ stock, Dr. Bill Theurkauff at UMass Worcester for the $m n k^{6006}$ stock, Dr. Eric Weischaus at Princeton University for the $\operatorname{grpz}^{5170} \operatorname{lok}^{30}$ and $g r p^{209} \operatorname{lok}^{30}$ lines, and Dr. Bruce McKee at the University of Tennessee for $P\{$ nos-GAL4::VP16\} and mei-w68 stocks. We appreciate the discussions provided by Dr. Bruce McKee and Dr. Albrecht von Arnim at the University of Tennessee, and a former Lab member Dr. Todd Schoborg for his support and several reagents. Also, we thank Tim Wesley for his help editing and making figures. The anti-Orb (4H8), lamin Dm0, Grk monoclonal antibodies, were developed by Drs. Paul Schedl, Paul A. Fisher, and Trudi Schupbach, respectively, and were obtained from the Developmental Studies Hybridoma Bank, created by the NICHD of the NIH and maintained at The University of Iowa, Department of Biology, Iowa City, IA 52242. 


\section{References}

Abbas, T., Shibata, E., Park, J., Jha, S., Karnani, N. and Dutta, A. (2010). CRL4(Cdt2)

regulates cell proliferation and histone gene expression by targeting PR-Set7/Set8 for degradation. Mol Cell 40, 9-21.

Abdu, U., Brodsky, M. and Schupbach, T. (2002). Activation of a meiotic checkpoint during Drosophila oogenesis regulates the translation of gurken through Chk2/Mnk. Current Biology 12, 1645-1651.

Andreyeva, E. N., Kolesnikova, T. D., Belyaeva, E. S., Glaser, R. L. and Zhimulev, I. F. (2008). Local DNA underreplication correlates with accumulation of phosphorylated H2Av in the Drosophila melanogaster polytene chromosomes. Chromosome Research 16, 851-62.

Aravin, A. A., Lagos-Quintana, M., Yalcin, A., Zavolan, M., Marks, D., Snyder, B., Gaasterland, T., Meyer, J. and Tuschl, T. (2003). The small RNA profile during Drosophila melanogaster development. Dev Cell 5, 337-50.

Bate, M. and Martinez Arias, A. (1993). The development of Drosophila melanogaster. Plainview, N.Y.: Cold Spring Harbor Laboratory Press.

Baxley, R. M., Soshnev, A. A., Koryakov, D. E., Zhimulev, I. F. and Geyer, P. K. (2011). The role of the Suppressor of Hairy-wing insulator protein in Drosophila oogenesis. Dev Biol 356, 398-410.

Beck, D. B., Burton, A., Oda, H., Ziegler-Birling, C., Torres-Padilla, M. E. and Reinberg, D. (2012a). The role of PR-Set7 in replication licensing depends on Suv4-20h. Genes Dev 26, 2580-9.

Beck, D. B., Oda, H., Shen, S. S. and Reinberg, D. (2012b). PR-Set7 and H4K20me1: at the crossroads of genome integrity, cell cycle, chromosome condensation, and transcription. Genes \& Development 26, 325-337.

Blythe, S. A. and Wieschaus, E. F. (2015). Zygotic genome activation triggers the DNA replication checkpoint at the midblastula transition. Cell 160, 1169-81.

Brasset, E. and Vaury, C. (2005). Insulators are fundamental components of the eukaryotic genomes. Heredity 94, 571-6. 
Brennecke, J., Aravin, A. A., Stark, A., Dus, M., Kellis, M., Sachidanandam, R. and Hannon, G. J. (2007). Discrete small RNA-generating loci as master regulators of transposon activity in Drosophila. Cell 128, 1089-1103.

Brodsky, M. H., Weinert, B. T., Tsang, G., Rong, Y. S., McGinnis, N. M., Golic, K. G., Rio, D. C. and Rubin, G. M. (2004). Drosophila melanogaster MNK/Chk2 and p53 regulate multiple DNA repair and apoptotic pathways following DNA damage. Mol Cell Biol 24, 1219-31.

Bushey, A. M., Ramos, E. and Corces, V. G. (2009). Three subclasses of a Drosophila insulator show distinct and cell type-specific genomic distributions. Genes \& Development 23, 1338-1350.

Butcher, R. D., Chodagam, S., Basto, R., Wakefield, J. G., Henderson, D. S., Raff, J. W. and Whitfield, W. G. (2004). The Drosophila centrosome-associated protein CP190 is essential for viability but not for cell division. Journal of Cell Science 117, 1191-9.

Canela, A., Maman, Y., Jung, S., Wong, N., Callen, E., Day, A., Kieffer-Kwon, K. R., Pekowska, A., Zhang, H., Rao, S. S. P. et al. (2017). Genome Organization Drives Chromosome Fragility. Cell 170, 507-521 e18.

Centore, R. C., Havens, C. G., Manning, A. L., Li, J. M., Flynn, R. L., Tse, A., Jin, J., Dyson, N. J., Walter, J. C. and Zou, L. (2010). CRL4(Cdt2)-mediated destruction of the histone methyltransferase Set8 prevents premature chromatin compaction in S phase. Mol Cell 40, 22-33.

Chen, Y., Pane, A. and Schupbach, T. (2007). Cutoff and aubergine mutations result in retrotransposon upregulation and checkpoint activation in Drosophila. Curr Biol 17, 637-42.

Cimprich, K. A. and Cortez, D. (2008). ATR: an essential regulator of genome integrity. Nat Rev Mol Cell Biol 9, 616-27.

Clegg, N. J., Findley, S. D., Mahowald, A. P. and Ruohola-Baker, H. (2001). maelstrom is required to position the MTOC in stage 2-6 Drosophila oocytes. Development Genes and Evolution 211, 44-48.

Clegg, N. J., Frost, D. M., Larkin, M. K., Subrahmanyan, L., Bryant, Z. and RuoholaBaker, H. (1997). maelstrom is required for an early step in the establishment of Drosophila oocyte polarity: posterior localization of grk mRNA. Development 124, 4661-4671. 
Cook, H. A., Koppetsch, B. S., Wu, J. and Theurkauf, W. E. (2004). The Drosophila SDE3 homolog armitage is required for oskar mRNA silencing and embryonic axis specification. Cell 116, 817-829.

Dej, K. J. and Spradling, A. C. (1999). The endocycle controls nurse cell polytene chromosome structure during Drosophila oogenesis. Development 126, 293-303.

Feschotte, C. (2008). Transposable elements and the evolution of regulatory networks. Nat Rev Genet 9, 397-405.

Fogarty, P., Campbell, S. D., Abu-Shumays, R., Phalle, B. S., Yu, K. R., Uy, G. L., Goldberg, M. L. and Sullivan, W. (1997). The Drosophila grapes gene is related to checkpoint gene chk1/rad27 and is required for late syncytial division fidelity. Curr Biol 7, 418-26.

Fudenberg, G., Imakaev, M., Lu, C., Goloborodko, A., Abdennur, N. and Mirny, L. A. (2016). Formation of Chromosomal Domains by Loop Extrusion. Cell Rep 15, 2038-49.

Gaszner, M. and Felsenfeld, G. (2006). Insulators: exploiting transcriptional and epigenetic mechanisms. Nat Rev Genet 7, 703-13.

Georgiev, P. and Kozycina, M. (1996). Interaction between mutations in the suppressor of Hairy wing and modifier of mdg4 genes of Drosophila melanogaster affecting the phenotype of gypsy-induced mutations. Genetics 142, 425-36.

Georgiev, P. G. and Gerasimova, T. I. (1989). Novel genes influencing the expression of the yellow locus and mdg4 (gypsy) in Drosophila melanogaster. Mol Gen Genet 220, 121-6.

Gerasimova, T. I., Gdula, D. A., Gerasimov, D. V., Simonova, O. and Corces, V. G. (1995). A Drosophila Protein That Imparts Directionality on a Chromatin Insulator Is an Enhancer of Position-Effect Variegation. Cell 82, 587-597.

Ghabrial, A., Ray, R. P. and Schupbach, T. (1998). okra and spindle-B encode components of the RAD52 DNA repair pathway and affect meiosis and patterning in Drosophila oogenesis.

Genes \& Development 12, 2711-2723.

Ghabrial, A. and Schupbach, T. (1999). Activation of a meiotic checkpoint regulates translation of Gurken during Drosophila oogenesis. Nature Cell Biology 1, 354-357. 
Ghosh, D., Gerasimova, T. I. and Corces, V. G. (2001). Interactions between the $\mathrm{Su}(\mathrm{Hw})$ and $\operatorname{Mod}(\mathrm{mdg} 4)$ proteins required for gypsy insulator function. EMBO J 20, 2518-27.

Golan, A., Pick, E., Tsvetkov, L., Nadler, Y., Kluger, H. and Stern, D. F. (2010).

Centrosomal Chk2 in DNA damage responses and cell cycle progression. Cell Cycle 9, 2647-56.

Gonzalez-Reyes, A., Elliott, H. and St Johnston, D. (1997). Oocyte determination and the origin of polarity in Drosophila: the role of the spindle genes. Development 124, 4927-37.

Gurudatta, B. V. and Corces, V. G. (2009). Chromatin insulators: lessons from the fly. Brief Funct Genomic Proteomic 8, 276-82.

Hammond, M. P. and Laird, C. D. (1985). Chromosome Structure and DNA-Replication in Nurse and Follicle Cells of Drosophila-Melanogaster. Chromosoma 91, 267-278.

Harrison, D. A., Gdula, D. A., Coyne, R. S. and Corces, V. G. (1993). A leucine zipper domain of the suppressor of Hairy-wing protein mediates its repressive effect on enhancer function. Genes Dev 7, 1966-78.

Harrison, D. A., Mortin, M. A. and Corces, V. G. (1992). The RNA polymerase II 15kilodalton subunit is essential for viability in Drosophila melanogaster. Mol Cell Biol 12, 928-35.

Heger, P. and Wiehe, T. (2014). New tools in the box: an evolutionary synopsis of chromatin insulators. Trends in Genetics 30, 161-71.

Hsu, S. J., Plata, M. P., Ernest, B., Asgarifar, S. and Labrador, M. (2015). The insulator protein Suppressor of Hairy wing is required for proper ring canal development during oogenesis in Drosophila. Dev Biol 403, 57-68.

Jang, J. K., Sherizen, D. E., Bhagat, R., Manheim, E. A. and McKim, K. S. (2003).

Relationship of DNA double-strand breaks to synapsis in Drosophila. Journal of Cell Science 116, 3069-3077.

Jorgensen, S., Elvers, I., Trelle, M. B., Menzel, T., Eskildsen, M., Jensen, O. N., Helleday, T., Helin, K. and Sorensen, C. S. (2007). The histone methyltransferase SET8 is required for Sphase progression. Journal of Cell Biology 179, 1337-1345.

Jorgensen, S., Schotta, G. and Sorensen, C. S. (2013). Histone H4 Lysine 20 methylation: key player in epigenetic regulation of genomic integrity. Nucleic Acids Research 41, 2797-2806. 
Joyce, E. F., Pedersen, M., Tiong, S., White-Brown, S. K., Paul, A., Campbell, S. D. and McKim, K. S. (2011). Drosophila ATM and ATR have distinct activities in the regulation of meiotic DNA damage and repair. Journal of Cell Biology 195, 359-367.

Karachentsev, D., Druzhinina, M. and Steward, R. (2007). Free and chromatin-associated mono-, di-, and trimethylation of histone H4-lysine 20 during development and cell cycle progression. Developmental Biology 304, 46-52.

Karachentsev, D., Sarma, K., Reinberg, D. and Steward, R. (2005). PR-Set7-dependent methylation of histone H4 Lys 20 functions in repression of gene expression and is essential for mitosis. Genes \& Development 19, 431-435.

Katokhin, A. V., Pindiurin, A. V., Fedorova, E. V. and Baricheva, E. M. (2001). [Molecular genetic analysis of Thrithorax-like gene encoded transcriptional factor GAGA in Drosophila melanogaster]. Genetika 37, 467-74.

Katsura, M., Tsuruga, T., Date, O., Yoshihara, T., Ishida, M., Tomoda, Y., Okajima, M., Takaku, M., Kurumizaka, H., Kinomura, A. et al. (2009). The ATR-Chk1 pathway plays a role in the generation of centrosome aberrations induced by Rad51C dysfunction. Nucleic Acids Res 37, 3959-68.

Kellum, R. and Schedl, P. (1991). A position-effect assay for boundaries of higher order chromosomal domains. Cell 64, 941-50.

Khurana, J. S. and Theurkauf, W. (2010). piRNAs, transposon silencing, and Drosophila germline development. Journal of Cell Biology 191, 905-913.

Kim, J., Kim, Y. J. and Kim-Ha, J. (2010). Blood-brain barrier defects associated with Rbp9 mutation. Mol Cells 29, 93-8.

Klattenhoff, C., Bratu, D. P., McGinnis-Schultz, N., Koppetsch, B. S., Cook, H. A. and Theurkauf, W. E. (2007). Drosophila rasiRNA pathway mutations disrupt embryonic axis specification through activation of an ATR/Chk2 DNA damage response. Developmental Cell $12,45-55$.

Klattenhoff, C., Xi, H., Li, C., Lee, S., Xu, J., Khurana, J. S., Zhang, F., Schultz, N., Koppetsch, B. S., Nowosielska, A. et al. (2009). The Drosophila HP1 homolog Rhino is 
required for transposon silencing and piRNA production by dual-strand clusters. Cell 138, 113749.

Klug, W. S., Bodenstein, D. and King, R. C. (1968). Oogenesis in the suppressor of hairy-wing mutant of Drosophila melanogaster. I. Phenotypic characterization and transplantation experiments. J Exp Zool 167, 151-6.

Klug, W. S., King, R. C. and Wattiaux, J. M. (1970). Oogenesis in the suppressor of hairywing mutant of Drosophila melanogaster. II. Nucleolar morphology and in vitro studies of RNA protein synthesis. $J$ Exp Zool 174, 125-40.

Klusza, S., Novak, A., Figueroa, S., Palmer, W. and Deng, W. M. (2013). Prp22 and spliceosome components regulate chromatin dynamics in germ-line polyploid cells. PLoS One $\mathbf{8}$, e79048.

Kugler, J. M. and Lasko, P. (2009). Localization, anchoring and translational control of oskar, gurken, bicoid and nanos mRNA during Drosophila oogenesis. Fly (Austin) 3, 15-28.

Labrador, M. and Corces, V. G. (2002). Setting the boundaries of chromatin domains and nuclear organization. Cell 111, 151-4.

Lankenau, D. H., Peluso, M. V. and Lankenau, S. (2000). The Su(Hw) chromatin insulator protein alters double-strand break repair frequencies in the Drosophila germ line. Chromosoma 109, 148-60.

LaRocque, J. R., Jaklevic, B., Su, T. T. and Sekelsky, J. (2007). Drosophila ATR in doublestrand break repair. Genetics 175, 1023-1033.

Laurencon, A., Purdy, A., Sekelsky, J., Hawley, R. S. and Su, T. T. (2003). Phenotypic analysis of separation-of-function alleles of MEI-41, Drosophila ATM/ATR. Genetics 164, 589601.

Lee, H. O., Davidson, J. M. and Duronio, R. J. (2009). Endoreplication: polyploidy with purpose. Genes Dev 23, 2461-77.

Lieberman-Aiden, E., van Berkum, N. L., Williams, L., Imakaev, M., Ragoczy, T., Telling, A., Amit, I., Lajoie, B. R., Sabo, P. J., Dorschner, M. O. et al. (2009). Comprehensive 
mapping of long-range interactions reveals folding principles of the human genome. Science 326, 289-93.

Lilly, M. A. and Spradling, A. C. (1996a). The Drosophila endocycle is controlled by Cyclin E and lacks a checkpoint ensuring S-phase completion. Genes Dev 10, 2514-26.

Lilly, M. A. and Spradling, A. C. (1996b). The Drosophila endocycle is controlled by cyclin E and lacks a checkpoint ensuring S-phase completion. Genes \& Development 10, 2514-2526.

Lu, L. and Tower, J. (1997). A transcriptional insulator element, the su(Hw) binding site, protects a chromosomal DNA replication origin from position effects. Molecular and Cellular Biology 17, 2202-2206.

Lupianez, D. G., Kraft, K., Heinrich, V., Krawitz, P., Brancati, F., Klopocki, E., Horn, D., Kayserili, H., Opitz, J. M., Laxova, R. et al. (2015). Disruptions of topological chromatin domains cause pathogenic rewiring of gene-enhancer interactions. Cell 161, 1012-1025.

Mata, J., Curado, S., Ephrussi, A. and Rorth, P. (2000). Tribbles coordinates mitosis and morphogenesis in Drosophila by regulating string/CDC25 proteolysis. Cell 101, 511-22.

McKim, K. S. and Hayashi-Hagihara, A. (1998). mei-W68 in Drosophila melanogaster encodes a Spo11 homolog: evidence that the mechanism for initiating meiotic recombination is conserved. Genes Dev 12, 2932-42.

Mehrotra, S. and McKim, K. S. (2006). Temporal analysis of meiotic DNA double-strand break formation and repair in Drosophila females. Plos Genetics 2, 1883-1897.

Mengoli, V., Bucciarelli, E., Lattao, R., Piergentili, R., Gatti, M. and Bonaccorsi, S. (2014).

The analysis of mutant alleles of different strength reveals multiple functions of topoisomerase 2 in regulation of Drosophila chromosome structure. PLoS Genet 10, e1004739.

Merigliano, C., Marzio, A., Renda, F., Somma, M. P., Gatti, M. and Verni, F. (2017). A

Role for the Twins Protein Phosphatase (PP2A-B55) in the Maintenance of Drosophila Genome Integrity. Genetics 205, 1151-1167.

Mirkin, E. V. and Mirkin, S. M. (2007). Replication fork stalling at natural impediments. Microbiol Mol Biol Rev 71, 13-35. 
Modolell, J., Bender, W. and Meselson, M. (1983). Drosophila melanogaster mutations suppressible by the suppressor of Hairy-wing are insertions of a 7.3-kilobase mobile element. Proc Natl Acad Sci U S A 80, 1678-82.

Mohan, M., Bartkuhn, M., Herold, M., Philippen, A., Heinl, N., Bardenhagen, I., Leers, J., White, R. A., Renkawitz-Pohl, R., Saumweber, H. et al. (2007). The Drosophila insulator proteins CTCF and CP190 link enhancer blocking to body patterning. EMBO J 26, 4203-14. Mohn, F., Sienski, G., Handler, D. and Brennecke, J. (2014). The rhino-deadlock-cutoff complex licenses noncanonical transcription of dual-strand piRNA clusters in Drosophila. Cell 157, 1364-79.

Moshkovich, N., Nisha, P., Boyle, P. J., Thompson, B. A., Dale, R. K. and Lei, E. P. (2011). RNAi-independent role for Argonaute2 in CTCF/CP190 chromatin insulator function. Genes Dev 25, 1686-701.

Negre, N., Brown, C. D., Shah, P. K., Kheradpour, P., Morrison, C. A., Henikoff, J. G., Feng, X., Ahmad, K., Russell, S., White, R. A. et al. (2010). A comprehensive map of insulator elements for the Drosophila genome. PLoS Genet 6, e1000814.

Neuman-Silberberg, F. S. and Schupbach, T. (1993). The Drosophila dorsoventral patterning gene gurken produces a dorsally localized RNA and encodes a TGF alpha-like protein. Cell 75, $165-74$.

Ong, C. T. and Corces, V. G. (2014). CTCF: an architectural protein bridging genome topology and function. Nat Rev Genet 15, 234-46.

Oomen, M. E., Hansen, A. S., Liu, Y., Darzacq, X. and Dekker, J. (2019). CTCF sites display cell cycle-dependent dynamics in factor binding and nucleosome positioning. Genome Res $\mathbf{2 9}$, 236-249.

Page, S. L. and Hawley, R. S. (2001). c(3)G encodes a Drosophila synaptonemal complex protein. Genes Dev 15, 3130-43.

Pai, C. Y., Lei, E. P., Ghosh, D. and Corces, V. G. (2004). The centrosomal protein CP190 is a component of the gypsy chromatin insulator. Mol Cell 16, 737-48. 
Parkhurst, S. M. and Corces, V. G. (1985). Forked, Gypsys, and Suppressors in Drosophila. Cell 41, 429-437.

Parkhurst, S. M. and Corces, V. G. (1986). Interactions among the Gypsy Transposable Element and the Yellow and the Suppressor of Hairy-Wing Loci in Drosophila-Melanogaster. Molecular and Cellular Biology 6, 47-53.

Parkhurst, S. M., Harrison, D. A., Remington, M. P., Spana, C., Kelley, R. L., Coyne, R. S. and Corces, V. G. (1988). The Drosophila Su(Hw) Gene, Which Controls the Phenotypic Effect of the Gypsy Transposable Element, Encodes a Putative DNA-Binding Protein. Genes \& Development 2, 1205-1215.

Peng, J. C. and Karpen, G. H. (2008). Epigenetic regulation of heterochromatic DNA stability. Curr Opin Genet Dev 18, 204-11.

Phillips-Cremins, J. E. and Corces, V. G. (2013). Chromatin Insulators: Linking Genome Organization to Cellular Function. Molecular Cell 50, 461-474.

Rao, S. S., Huntley, M. H., Durand, N. C., Stamenova, E. K., Bochkov, I. D., Robinson, J. T., Sanborn, A. L., Machol, I., Omer, A. D., Lander, E. S. et al. (2014). A 3D Map of the Human Genome at Kilobase Resolution Reveals Principles of Chromatin Looping. Cell 159, $1665-80$.

Rorth, P. (1998). Gal4 in the Drosophila female germline. Mech Dev 78, 113-8.

Roseman, R. R., Pirrotta, V. and Geyer, P. K. (1993). The su(Hw) protein insulates expression of the Drosophila melanogaster white gene from chromosomal position-effects. EMBO J 12, 435-42.

Rowley, M. J., Nichols, M. H., Lyu, X., Ando-Kuri, M., Rivera, I. S. M., Hermetz, K., Wang, P., Ruan, Y. and Corces, V. G. (2017). Evolutionarily Conserved Principles Predict 3D Chromatin Organization. Mol Cell 67, 837-852 e7.

Roy, S., Gilbert, M. K. and Hart, C. M. (2007). Characterization of BEAF mutations isolated by homologous recombination in Drosophila. Genetics 176, 801-13. 
Sakaguchi, A., Joyce, E., Aoki, T., Schedl, P. and Steward, R. (2012). The Histone H4 Lysine 20 Monomethyl Mark, Set by PR-Set7 and Stabilized by L(3)mbt, Is Necessary for Proper Interphase Chromatin Organization. PLoS One 7.

Sakaguchi, A. and Steward, R. (2007). Aberrant monomethylation of histone H4 lysine 20 activates the DNA damage checkpoint in Drosophila melanogaster. J Cell Biol 176, 155-62.

Sancar, A., Lindsey-Boltz, L. A., Unsal-Kacmaz, K. and Linn, S. (2004). Molecular mechanisms of mammalian DNA repair and the DNA damage checkpoints. Annual Review of Biochemistry 73, 39-85.

Sato, K., Nishida, K. M., Shibuya, A., Siomi, M. C. and Siomi, H. (2011). Maelstrom coordinates microtubule organization during Drosophila oogenesis through interaction with components of the MTOC. Genes Dev 25, 2361-73.

Schindelin, J., Arganda-Carreras, I., Frise, E., Kaynig, V., Longair, M., Pietzsch, T., Preibisch, S., Rueden, C., Saalfeld, S., Schmid, B. et al. (2012). Fiji: an open-source platform for biological-image analysis. Nat Methods 9, 676-82.

Schoborg, T. and Labrador, M. (2014). Expanding the roles of chromatin insulators in nuclear architecture, chromatin organization and genome function. Cell Mol Life Sci 71, 4089-113.

Schoborg, T., Rickels, R., Barrios, J. and Labrador, M. (2013). Chromatin insulator bodies are nuclear structures that form in response to osmotic stress and cell death. J Cell Biol 202, 26176.

Schoborg, T. A. and Labrador, M. (2010). The phylogenetic distribution of non-CTCF insulator proteins is limited to insects and reveals that BEAF-32 is Drosophila lineage specific. $J$ Mol Evol 70, 74-84.

Shimada, M. and Komatsu, K. (2009). Emerging connection between centrosome and DNA repair machinery. J Radiat Res 50, 295-301.

Sibon, O. C., Stevenson, V. A. and Theurkauf, W. E. (1997). DNA-replication checkpoint control at the Drosophila midblastula transition. Nature 388, 93-7. 
Sienski, G., Donertas, D. and Brennecke, J. (2012). Transcriptional Silencing of Transposons by Piwi and Maelstrom and Its Impact on Chromatin State and Gene Expression. Cell 151, 964980.

Sirbu, B. M. and Cortez, D. (2013). DNA damage response: three levels of DNA repair regulation. Cold Spring Harb Perspect Biol 5, a012724.

Smith, E. M., Lajoie, B. R., Jain, G. and Dekker, J. (2016). Invariant TAD Boundaries Constrain Cell-Type-Specific Looping Interactions between Promoters and Distal Elements around the CFTR Locus. Am J Hum Genet 98, 185-201.

Soshnev, A. A., Baxley, R. M., Manak, J. R., Tan, K. and Geyer, P. K. (2013). The insulator protein Suppressor of Hairy wing is an essential transcriptional repressor in the Drosophila ovary. Development.

Soshnev, A. A., He, B., Baxley, R. M., Jiang, N., Hart, C. M., Tan, K. and Geyer, P. K. (2012). Genome-wide studies of the multi-zinc finger Drosophila Suppressor of Hairy-wing protein in the ovary. Nucleic Acids Res 40, 5415-31.

Spana, C., Harrison, D. A. and Corces, V. G. (1988). The Drosophila-MelanogasterSuppressor of Hairy-Wing Protein Binds to Specific Sequences of the Gypsy Retrotransposon. Genes \& Development 2, 1414-1423.

Staeva-Vieira, E., Yoo, S. and Lehmann, R. (2003). An essential role of DmRad51/SpnA in DNA repair and meiotic checkpoint control. EMBO J 22, 5863-74.

Steinhauer, J. and Kalderon, D. (2006). Microtubule polarity and axis formation in the Drosophila oocyte. Developmental Dynamics 235, 1455-1468.

Sullivan, W., Ashburner, M. and Hawley, R. S. (2000). Drosophila protocols. Cold Spring Harbor, NY: Cold Spring Harbor Laboratory Press.

Tardat, M., Brustel, J., Kirsh, O., Lefevbre, C., Callanan, M., Sardet, C. and Julien, E. (2010a). The histone H4 Lys 20 methyltransferase PR-Set7 regulates replication origins in mammalian cells. Nat Cell Biol 12, 1086-93. 
Tardat, M., Brustel, J., Kirsh, O., Lefevbre, C., Callanan, M., Sardet, C. and Julien, E. (2010b). The histone H4 Lys 20 methyltransferase PR-Set7 regulates replication origins in mammalian cells. Nature Cell Biology 12, 1086-U82.

Tardat, M., Murr, R., Herceg, Z., Sardet, C. and Julien, E. (2007). PR-Set7-dependent lysine methylation ensures genome replication and stability through S phase. J Cell Biol 179, 1413-26.

Theurkauf, W. E., Smiley, S., Wong, M. L. and Alberts, B. M. (1992). Reorganization of the cytoskeleton during Drosophila oogenesis: implications for axis specification and intercellular transport. Development 115, 923-36.

Tracey, W. D., Jr., Ning, X., Klingler, M., Kramer, S. G. and Gergen, J. P. (2000).

Quantitative analysis of gene function in the Drosophila embryo. Genetics 154, 273-84.

Udvardy, A., Maine, E. and Schedl, P. (1985). The 87A7 chromomere. Identification of novel chromatin structures flanking the heat shock locus that may define the boundaries of higher order domains. J Mol Biol 185, 341-58.

Van Bortle, K. and Corces, V. G. (2012a). Nuclear Organization and Genome Function. Annual Review of Cell and Developmental Biology, Vol 28 28, 163-187.

Van Bortle, K. and Corces, V. G. (2012b). tDNA insulators and the emerging role of TFIIIC in genome organization. Transcription 3, 277-84.

Van Doren, M., Williamson, A. L. and Lehmann, R. (1998). Regulation of zygotic gene expression in Drosophila primordial germ cells. Current Biology 8, 243-246.

Volpe, A. M., Horowitz, H., Grafer, C. M., Jackson, S. M. and Berg, C. A. (2001).

Drosophila rhino encodes a female-specific chromo-domain protein that affects chromosome structure and egg polarity. Genetics 159, 1117-34.

Vorobyeva, N. E., Mazina, M. U., Golovnin, A. K., Kopytova, D. V., Gurskiy, D. Y., Nabirochkina, E. N., Georgieva, S. G., Georgiev, P. G. and Krasnov, A. N. (2013). Insulator protein $\mathrm{Su}(\mathrm{Hw})$ recruits $\mathrm{SAGA}$ and Brahma complexes and constitutes part of Origin Recognition Complex-binding sites in the Drosophila genome. Nucleic Acids Research 41, 57175730. 
Wang, Y., Mijares, M., Gall, M. D., Turan, T., Javier, A., Bornemann, D. J., Manage, K. and Warrior, R. (2010). Drosophila variable nurse cells encodes arrest defective 1 (ARD1), the catalytic subunit of the major N-terminal acetyltransferase complex. Dev Dyn 239, 2813-27.

West, A. G., Gaszner, M. and Felsenfeld, G. (2002). Insulators: many functions, many mechanisms. Genes Dev 16, 271-88.

Wu, S. M. and Rice, J. C. (2011). A new regulator of the cell cycle The PR-Set7 histone methyltransferase. Cell Cycle 10, 68-72.

Yang, J. and Corces, V. G. (2012). Insulators, long-range interactions, and genome function. Curr Opin Genet Dev 22, 86-92.

Yarosh, W. and Spradling, A. C. (2014). Incomplete replication generates somatic DNA alterations within Drosophila polytene salivary gland cells. Genes Dev 28, 1840-55.

Yin, H. and Lin, H. F. (2007). An epigenetic activation role of Piwi and a Piwi-associated piRNA in Drosophila melanogaster. Nature 450, 304-U16.

Zeman, M. K. and Cimprich, K. A. (2014). Causes and consequences of replication stress. Nat Cell Biol 16, 2-9.

Zhao, K., Hart, C. M. and Laemmli, U. K. (1995). Visualization of chromosomal domains with boundary element-associated factor BEAF-32. Cell 81, 879-89.

\section{Figure legends}

Figure 1. A fraction of egg chambers in $s u(H w)$ mutants exhibit an irregular number of nurse cells. Wildtype and mutant egg chambers were stained with lamin antibody (green) and phalloidin (red), and nurse cell numbers were quantified. (A) A wildtype egg chamber with 15 
nurse cells. (B) A $s u(H w)^{v / e 04061}$ egg chamber with less than 15 nurse cells. (C) A $s u(H w)^{v / e 04061}$ egg chamber with more than 15 nurse cells. (D) More than 15 nurse cells in $a s u(H w)^{e 04061 / e 04061}$ egg chamber. Scale bars are $50 \mu \mathrm{m}$. (E) $s u(H w)^{v} / T M 6 B, s u(H w)^{v / e 04061}$, and $s u(H w):: e G F P$, nanos-GAL4; $s u(H w)^{v / e 04061}$ rescued individual egg chambers were documented in a table. The difference between wildtype and mutant as well as mutant and rescued flies are statistically significant ( $\mathrm{p}<0.05$, Fisher's exact test). (F) The number of ring canals in $s u(H w)^{v / e 04061}$ mutants with greater than or less than 15 nurse cells were documented.

Figure 2. The MTOC is impaired in $\operatorname{su}(\mathrm{Hw})$ mutants. Microtubules are labeled with $\alpha$-tubulin antibody (green). (A-D) Germarium stage egg chambers with different genotypes. Arrowheads indicate stage 1 egg chambers. (E-H) Egg chambers are magnified showing a dimmer and less bright MTOC (white arrowheads) in $s u(H w)^{v / e 04061}$ mutant chambers. Scale bars are $10 \mu \mathrm{m}$.

Figure 3. Gurken mislocalizes in $\boldsymbol{s u}(\mathrm{Hw})$ mutant egg chambers. Grk was labeled in green and its location was monitored at stage $6(*)$ and $9(* *)$ egg chambers. (A-C) In wildtype, Grk localizes at the posterior of the oocyte at stage 6 (inset B) and translocates to the dorsal-anterior corner at stage 9 (inset C). (D-F) Grk mislocalizes to the oocyte anterior at stage 9 in $s u(H w)^{v /}$ ${ }^{e 04061}$ mutant. E and F are insets from D.

Figure 4. Non-meiotic DNA damage accumulates in $s u(H w)$ mutant ovaries. DNA damage was visualized using an anti- $\gamma \mathrm{H} 2 \mathrm{Av}$ antibody (red) in early germaria and later stage egg chambers. Anti-C(3)G (green), a synaptonemal complex protein, was used as a marker to identify pro-oocytes and regions $2 \mathrm{a}$ and $2 \mathrm{~b}$ in ovarioles. Arrowheads point to stage 1 egg 
chambers. (A-H) Stage 1 egg chambers showing detail of nurse cells, oocytes, and $\gamma \mathrm{H} 2 \mathrm{Av}$ foci in different genotypes. Scale bar in $\mathrm{H}$ is $10 \mu \mathrm{m}$. (I-J) $\gamma \mathrm{H} 2 \mathrm{Av}$ foci were detected in $s u(H w)^{v / e 04061}$ through oogenesis. The Orb staining in green indicates the location of the oocyte within the egg chambers and $\gamma \mathrm{H} 2 \mathrm{Av}$ was observed to be relatively stronger in $s u(H w)^{v / e 04061}$ mutants compared to wildtype. The scale bar is $20 \mu \mathrm{m}$. (K) Diagram representing different stages of oogenesis in the Drosophila germarium.

Figure 5. Expression of transposable elements does not increase significantly in $\boldsymbol{s u}(\boldsymbol{H w})$ mutant ovaries: Transcript levels of seventeen transposable elements were quantified by real-time PCR and were normalized using rp49 as a control. Fold change values represent the relative expression of mRNA in ovaries from $s u(H w)^{e 04061}$ homozygotes compared with ovaries from $s u(H w)^{e 04061} / T M 6 B$ heterozygotes. One asterisk indicates $\mathrm{P}<0.05$ and two for $\mathrm{P}<0.0001$.

Figure 6. Oogenesis failure in $s u(H w)^{v / e 04061}$ mutants is partially rescued by mei-41 ${ }^{D 5}$ (ATR) and $\operatorname{grp}^{z 5170 / 209}$ (Chk1) mutations. Grk (green) was detected in egg chambers. (A-G) A $s u(H w)^{v} / T M 6 B$ egg chamber with normal Grk signaling (A), $s u(H w)^{v / e 04061}$ egg chamber with Grk mislocalization (B), mei4 $1^{D 5} ; s u(H w)^{v / e 04061}$ egg chamber with rescued Grk localization (C), $\operatorname{grp}^{25170 / 209} \operatorname{lok}^{30} ; \mathrm{su}(\mathrm{Hw})^{\mathrm{v} / \mathrm{e} 04061}$ egg chamber with rescued Grk localization (D), lok ${ }^{30} m n k^{6006}$; $s u(H w)^{v / e 04061}$ egg chamber with Grk mislocalization (E), a $m n k^{6006} ; s u(H w)^{v / e 04061}$ egg chamber with Grk mislocalization $(\mathrm{F})$, and a $\operatorname{grp}{ }^{z 5170 / 209} ; s u(H w)^{v / e 04061}$ egg chamber with rescued Grk localization $(\mathrm{G})$ are shown. $(\mathrm{H}) \mathrm{A} m e i-41^{D 5}, s u(H w)^{v / e 04061}$ double mutant egg chamber at stage

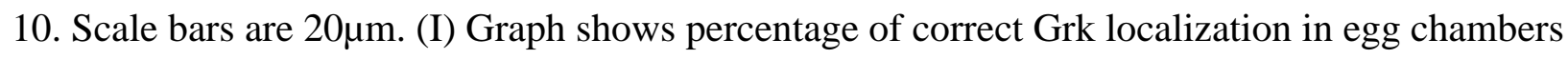
from each genotype. 
Figure 7. Expression of $\mathrm{Su}(\mathrm{Hw})$ in germline cells rescues female fertility and partially rescues embryo development. Wildtype virgin females and rescued females expressing either nanos-GAL4 driven $s u(H w):: e G F P$ or nos-GAL4 driven $s u(H w):: e G F P$ were crossed with wildtype male flies for three days and eggs were collected. (A) Different dorsoventral phenotypes of embryos in the offspring were categorized as Type I to IV, and the percentage of each category of embryos is shown in the stacked column graph. (B) $s u(H w)^{v} / T M 6 B$ female flies produced $97 \%$ type I, $2 \%$ type II, and $1 \%$ type IV embryos; however nanos-GAL4 driven $s u(H w):: e G F P$ rescued flies have only $24 \%$ type I (two normal appendages), $44 \%$ type II (two short appendages), $21 \%$ type III (one appendage), and 11\% type IV (no appendage), while nosGAL4 driven $s u(H w):: e G F P$ rescued flies have $0 \%$ type I, 3\% type II, $64 \%$ type III, and 33\% type IV. Sterile $s u(H w)$ mutant females were used as negative control. (C) Grk localization in rescued egg chambers. In nanos-GAL4 driven $s u(H w):: e G F P$ rescued flies $(\mathrm{N}=7), 71 \%$ of egg chambers had correct Grk localization, but in nos-GAL4 driven $s u(H w):: e G F P$ rescued flies only $18 \%$ egg chambers had normal Grk localization $(\mathrm{N}=11)$. ( $\mathrm{D}$ and $\mathrm{E})$. Grk localization in stage 9 egg chambers from rescued females. Arrowheads point to Grk. Green signal in nurse cell nuclei, in D, corresponds to GFP signal from $s u(H w):: e G F P$.

\section{Figure 8. Levels of $\gamma \mathrm{H} 2 \mathrm{Av}$ and $\mathrm{H} 4 \mathrm{~K} 20 \mathrm{me} 1$ are increased in $s u(\mathrm{Hw})$ mutant ovaries. (A-B)}

Western blot analysis of $\gamma \mathrm{H} 2 \mathrm{Av}$ and H4K20me1 in wildtype and mei-41 ${ }^{D 5} s u(H w)$ mutant ovary extracts. (A) Increased $\gamma \mathrm{H} 2 \mathrm{Av}$ is detected in $s u(H w)^{v / e 04061}$ and $m e i-41^{D 5} ; s u(H w)^{v / e 04061}$ double mutants, compared to wildtype $\left(s u(H w)^{v} / T M 6 B\right)$. Lamin was used as a loading control. (B) H4K20me1 levels increase in $s u(H w)^{v / e 04061}$ compared to wildtype $\left(s u(H w)^{v} / T M 6 B\right)$. 
Figure 9. Mutation of $s u(H w)$ is associated with chromosomal aberrations (CABs). (A)

Examples of wild type chromosomes (A1, labelled with chromosome numbers) and those with chromosomal aberrations (A2-A6). Chromatid deletions (A2) and isochromatid deletions (A3) are frequently found in $s u(H w)$ mutant backgrounds. (A4-A6) Genomes showing multiple CABs per cell. White arrows denote the sites of chromosomal breaks. (B) The fraction of cells showing CABs from each brain according to genotype. (C) A significant frequency of chromosomal aberrations is seen in $s u(H w)^{e 04061}$ homozygotes and $s u(H w)^{v / e 04061}$ transheterozygotes but not for wild-type or $s u(H w)^{e 04061}$ heterozygotes. Error bars represent one standard error. $* \mathrm{p}<0.05, * * \mathrm{p}<0.005$.

\section{Figure 10. An ATR/Chk1 checkpoint activation pathway is activated during replication} stress in ovaries from $s u(H w)$ mutant females. Three known causes of DNA damage during oogenesis are shown: meiotic recombination, transposable elements, and replication stress. Mutation of genes encoding DSB repair proteins or helicase (spindle mutants, left) disable the mechanisms that repair meiotic DSBs generated at an early stage of oogenesis. Overactivated Transposable Elements (TEs) may produce an excess of DSBs. This type of DSBs is usually observed in piRNA pathway mutants. In both spindle mutants and piRNA pathway mutants, unrepaired DSBs activate an ATR/Chk2 dependent DNA damage checkpoint that leads to a sequence of developmental defects, including microtubule disorganization, Grk mislocalization, Grk repression, and patterning defects in eggshells. In $s u(H w)$ mutant females, replication stress induces DNA damage during endoreplication (red pathway) and activates an ATR/Chk1 checkpoint that leads to Grk mislocalization and dorsoventral transformations. 
Figure S1. Quantification of ring canals in $s u(H w)^{v / e 04061}$ egg chambers with abnormal nurse cell number. The number of ring canals in egg chambers with either $<15$ nurse cells (top) or $>15$ nurse cells was quantified. $33 \%$ of egg chambers with $<15$ nurse cells contained $<4$ ring canals, whereas $66 \%$ contained 4 ring canals. $100 \%$ of egg chambers with $>15$ nurse cells contained $>4$ ring canals.

Figure S2. Staging of egg chambers for Grk localization experiments. The length of stage 9 (S9) egg chambers was first measured in wildtype flies. Egg chambers used for localization of Grk in mutant females is not significantly different from S9 egg chambers in wildtype. Egg chamber length was measured in arbitrary units. Comparisons between genotypes were performed using two-tailed Mann-Whitney t-tests. 
bioRxiv preprint doi: https://doi.org/10.1101/551002; this version posted February 15,2019 . The copyright holder for this preprint (which was not certified by peer review) is the author/funder, who has granted bioRxiv a license to display the preprint in perpetuity. It is made available under aCC-BY-NC-ND 4.0 International license.
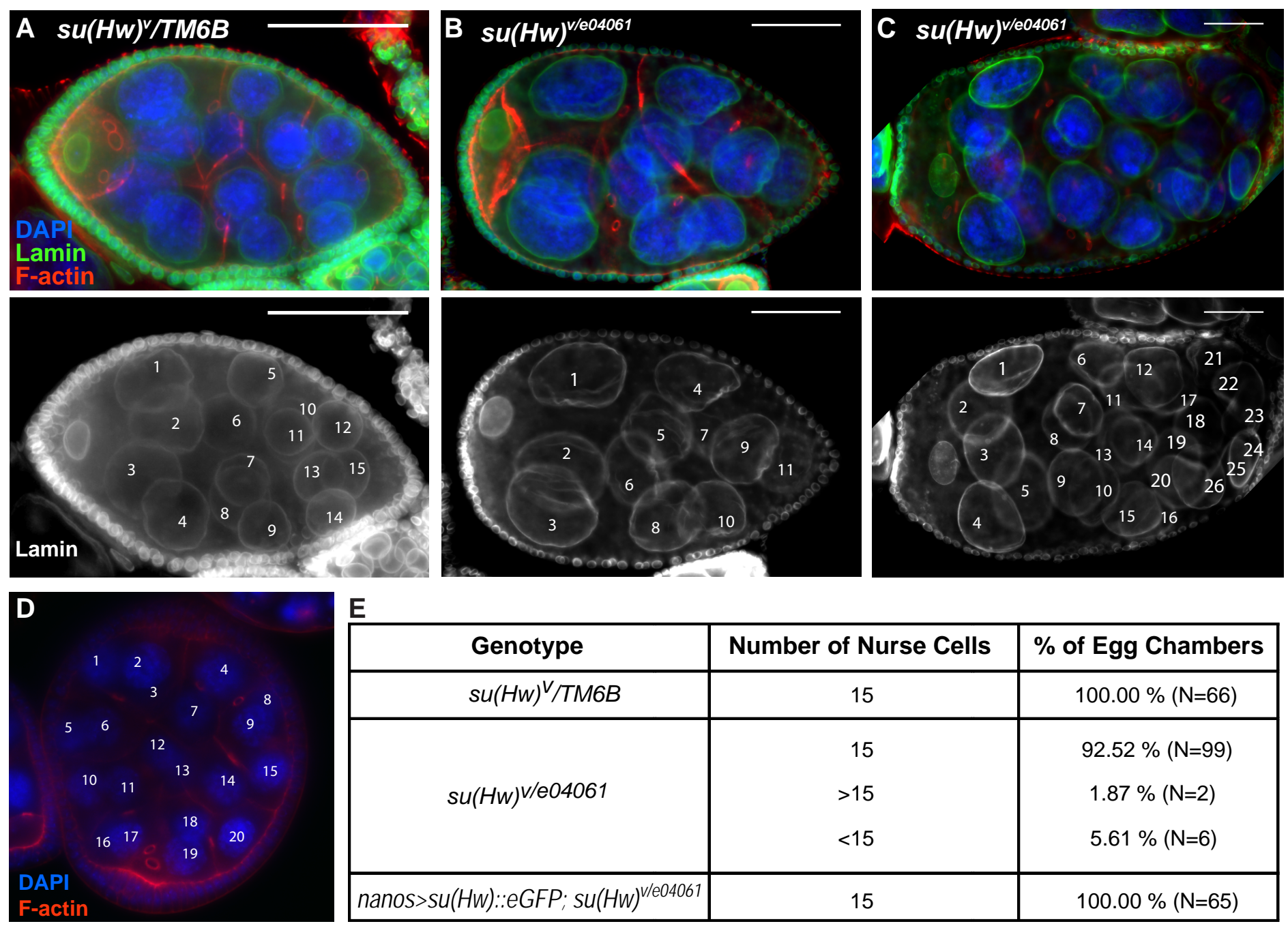

\begin{tabular}{|c|c|c|}
\hline Eenotype & Number of Nurse Cells & \% of Egg Chambers \\
\hline$s u(H w)^{V} / T M 6 B$ & 15 & $100.00 \%(\mathrm{~N}=66)$ \\
\hline & 15 & $92.52 \%(\mathrm{~N}=99)$ \\
$\mathrm{su}(H w)^{v / e 04061}$ & $>15$ & $1.87 \%(\mathrm{~N}=2)$ \\
& $<15$ & $5.61 \%(\mathrm{~N}=6)$ \\
\hline nanos>su(Hw)::eGFP; su(Hw) $)^{v / 204061}$ & 15 & $100.00 \%(\mathrm{~N}=65)$ \\
\hline
\end{tabular}

Figure 1 Hsu et al. 
bioRxiv preprint doi: https://doi.org/10.1101/551002; this version posted February 15, 2019. The copyright holder for this preprint (which was not certified by peer review) is the author/funder, who has granted bioRxiv a license to display the preprint in perpetuity. It is made available under aCC-BY-NC-ND 4.0 International license.

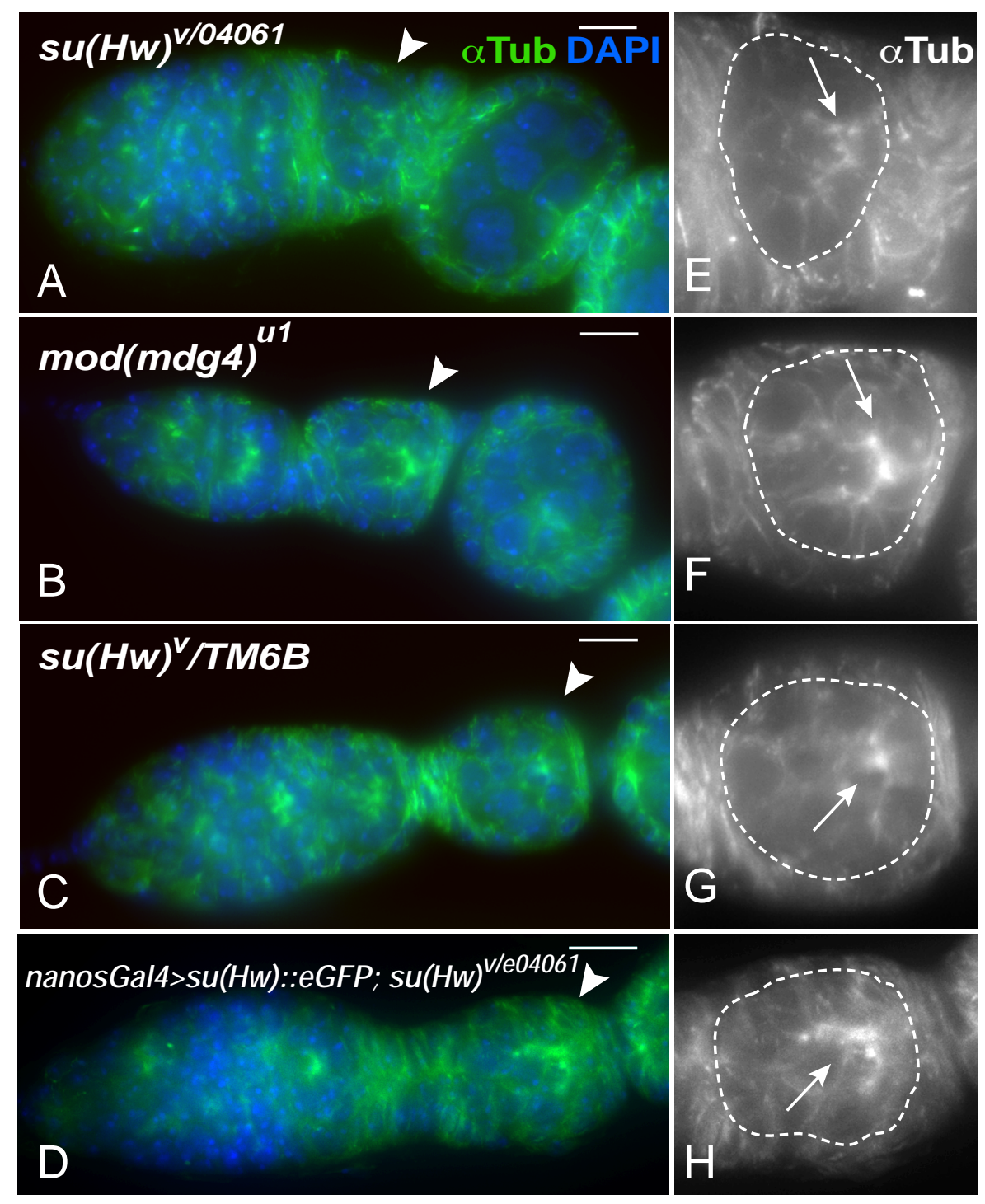

Figure 2 Hsu et al. 


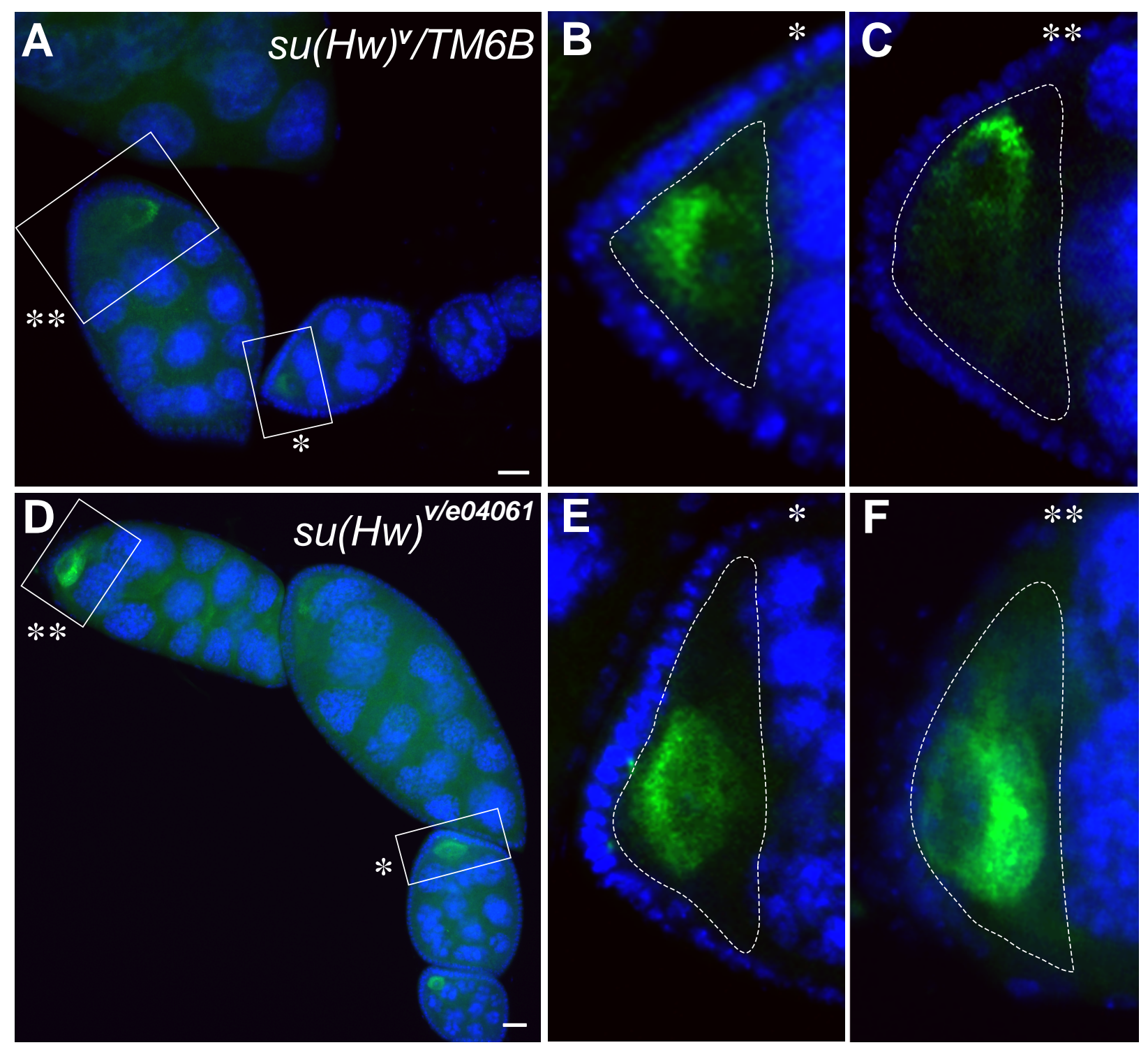

Figure 3 Hsu et al. 

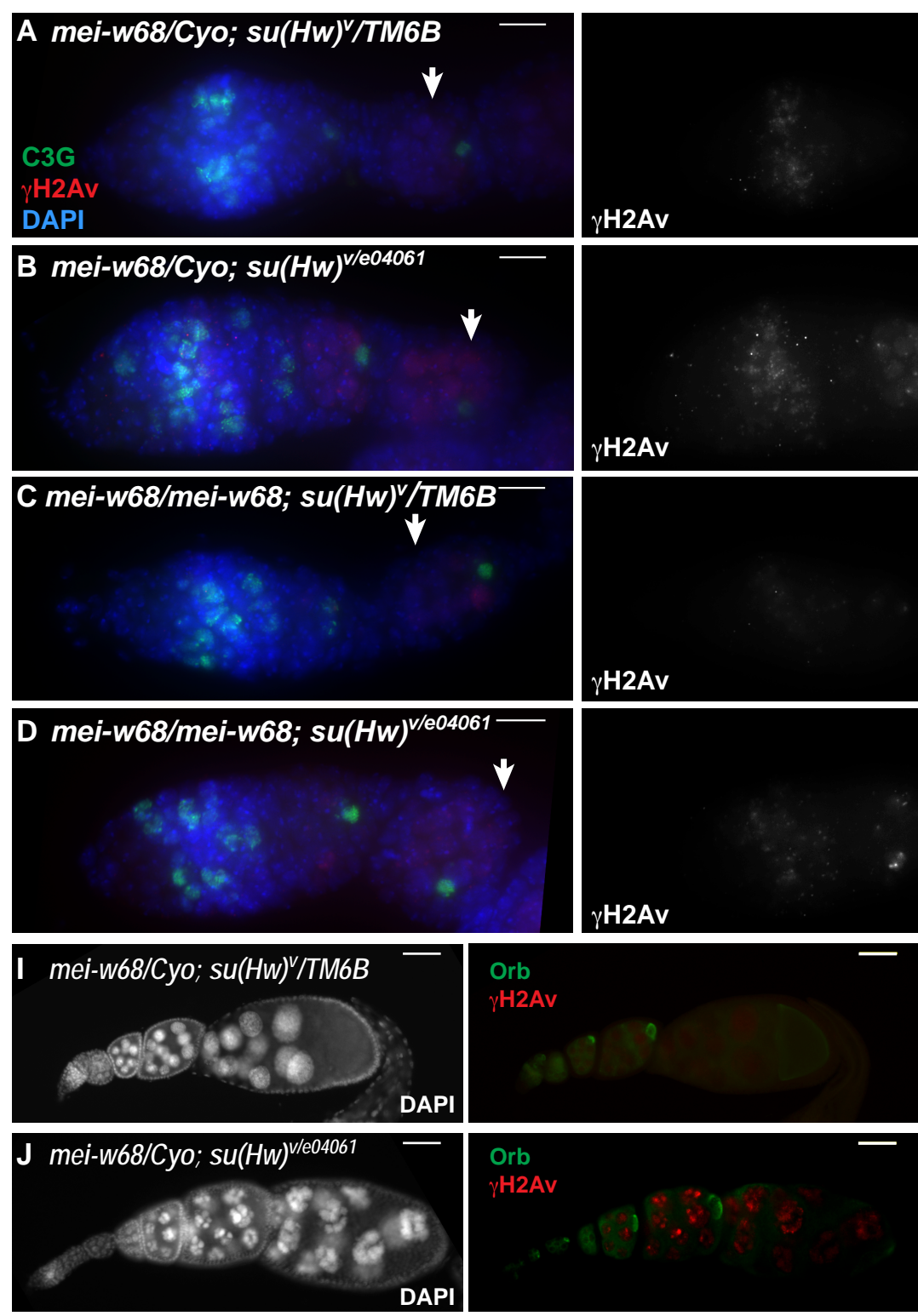

K

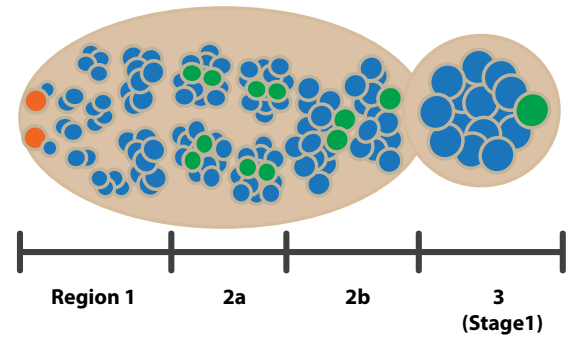

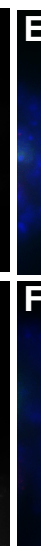

\section{$\gamma \mathrm{H} 2 \mathrm{Av}$}

$\gamma \mathrm{H} 2 \mathrm{Av}$
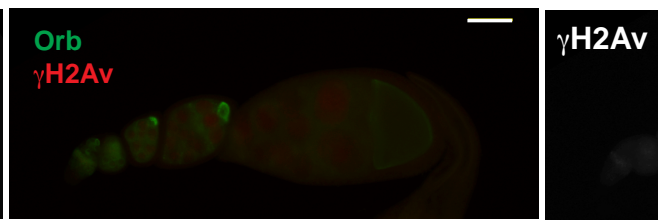

$\gamma \mathrm{H} 2 \mathrm{Av}$

\section{Germline stem cell}

Oocyte

cystoblast

-
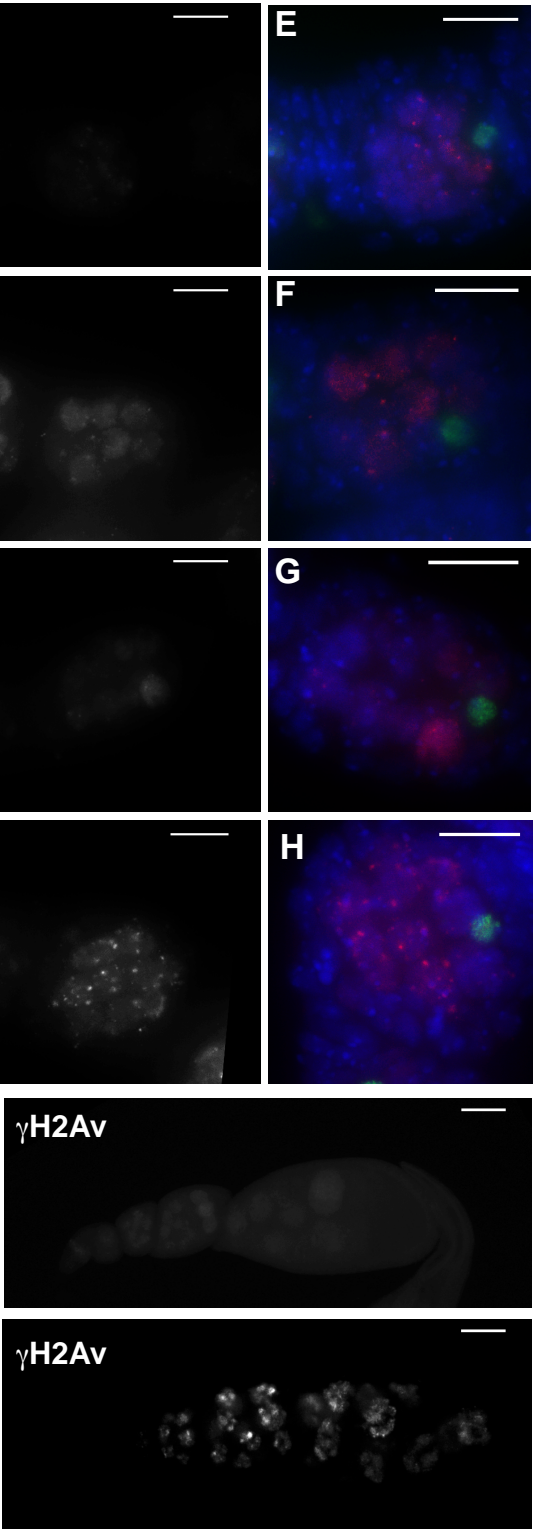

Figure 4 Hsu et al. 
bioRxiv preprint doi: https://doi.org/10.1101/551002; this version posted February 15, 2019. The copyright holder for this preprint (which was not certified by peer review) is the author/funder, who has granted bioRxiv a license to display the preprint in perpetuity. It is made available under aCC-BY-NC-ND 4.0 International license.

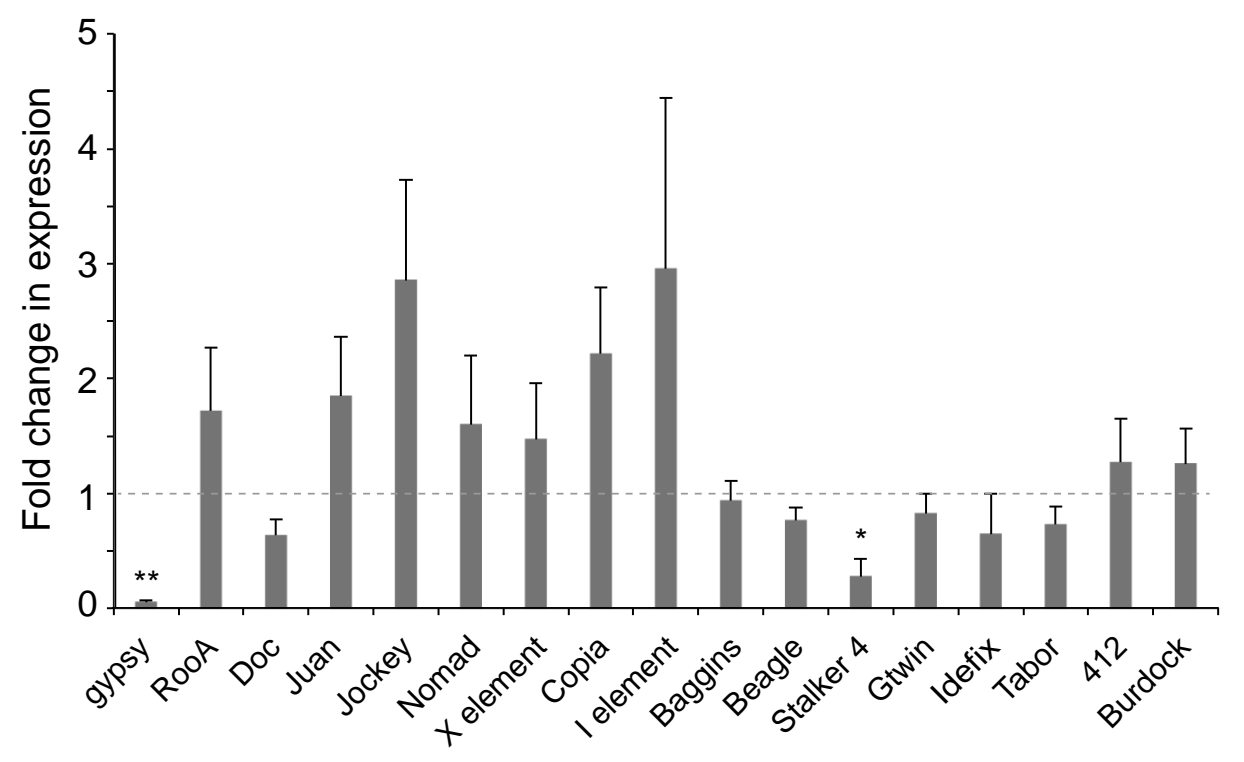

Figure 5 Hsu et al 
bioRxiv preprint doi: https://doi.org/10.1101/551002; this version posted February 15,2019 . The copyright holder for this preprint (which was not certified by peer review) is the author/funder, who has granted bioRxiv a license to display the preprint in perpetuity. It is made available under aCC-BY-NC-ND 4.0 International license.
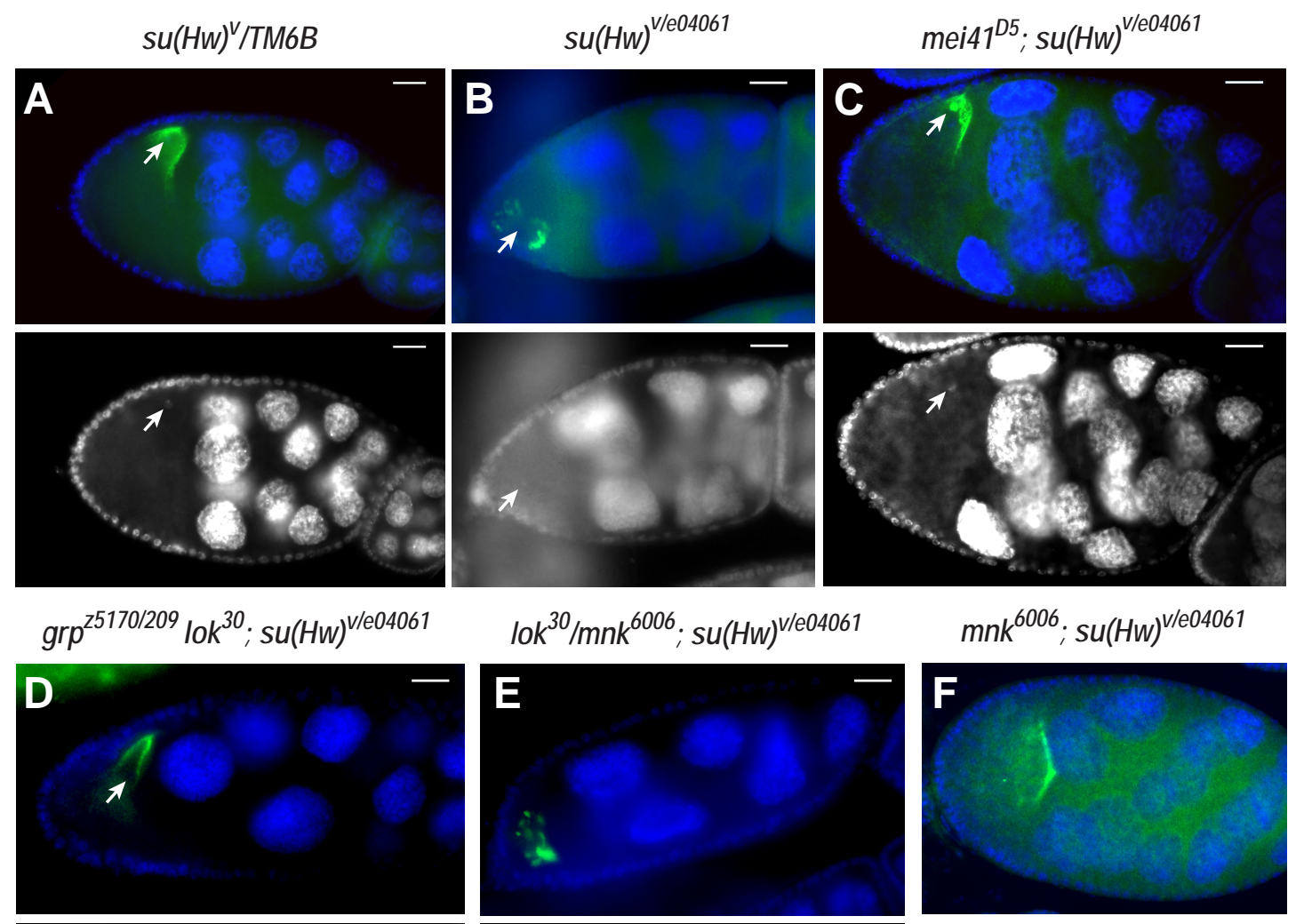

$$
m n k^{6006} ; s u(H w)^{v / e 04061}
$$
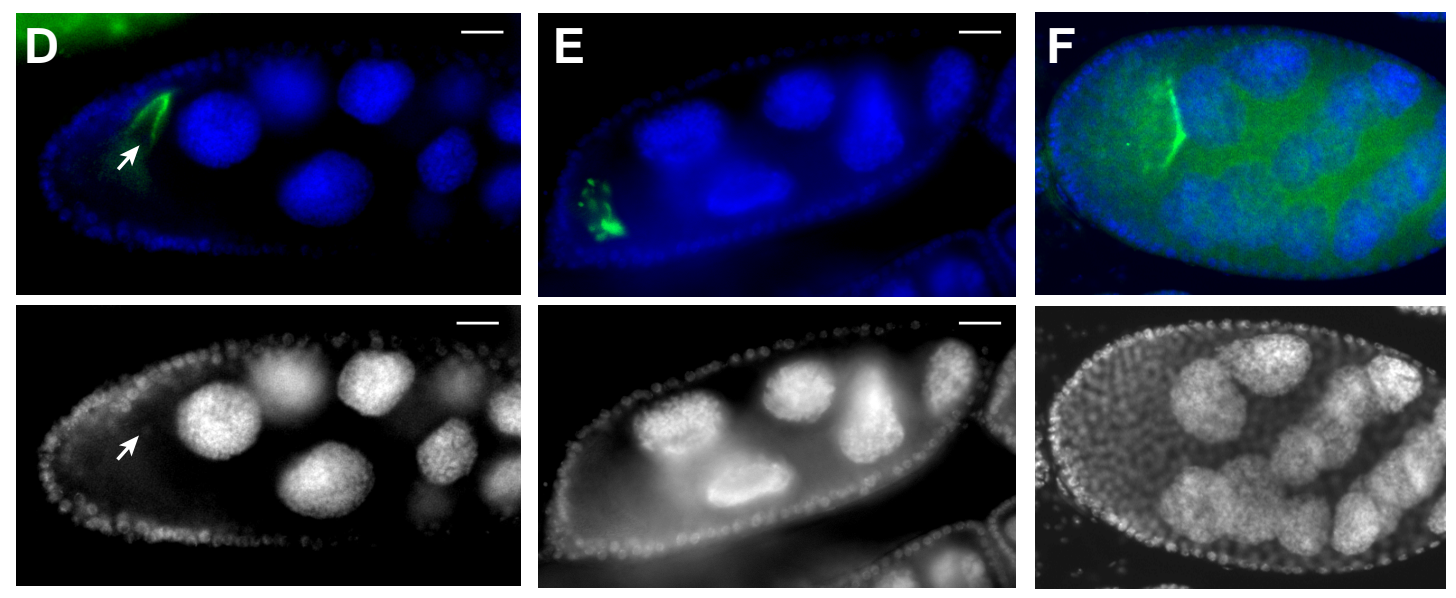

$$
\operatorname{grp}^{25170 / 209} ; \mathrm{su}(\mathrm{Hw})^{\mathrm{v} / \mathrm{e} 04061}
$$
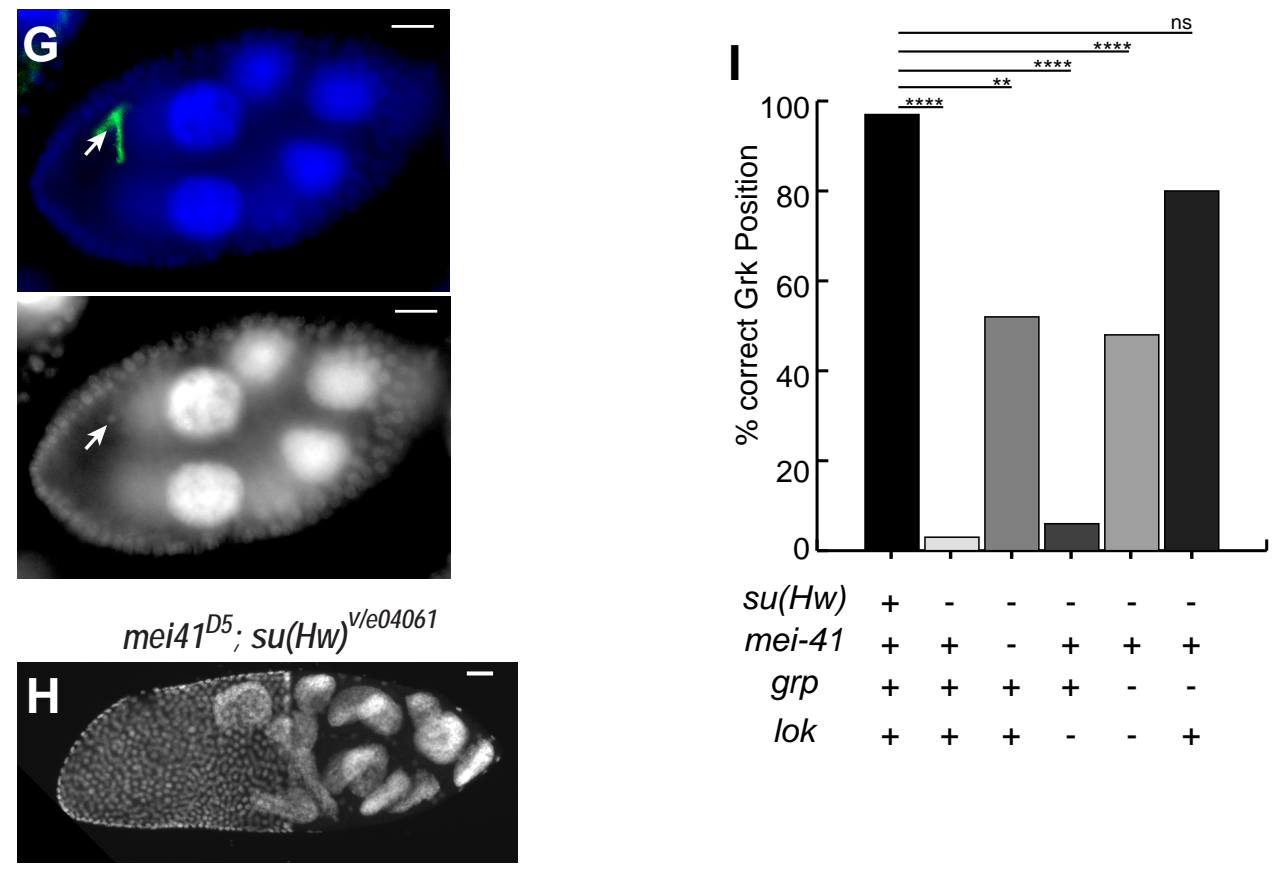

Figure 6 Hsu et al. 


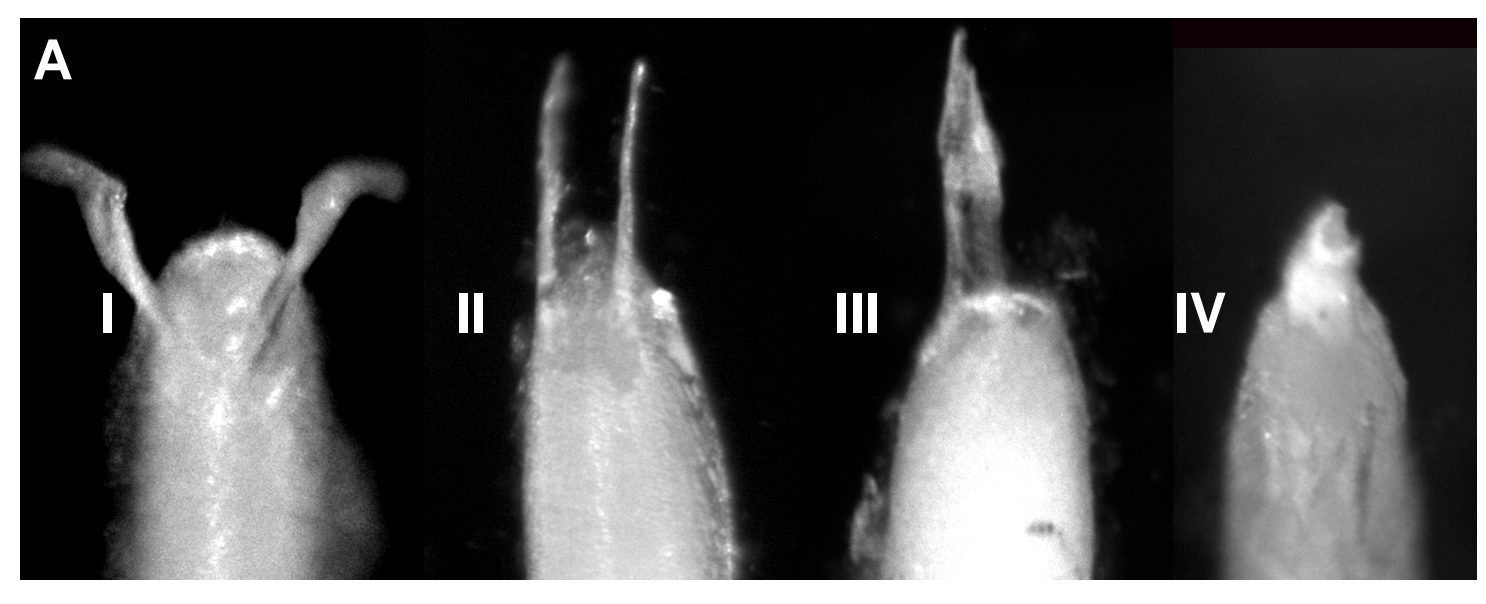

\section{B}

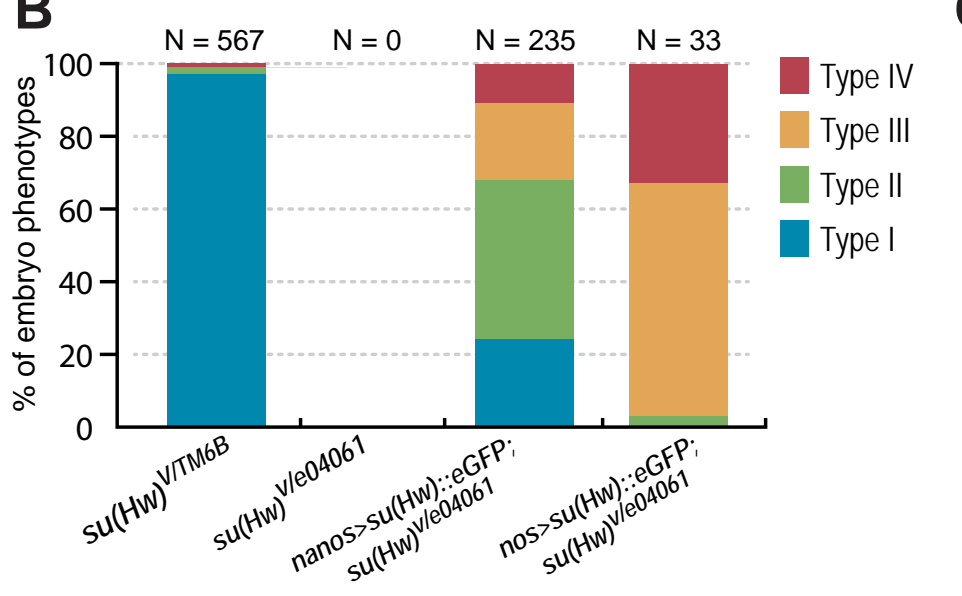

C

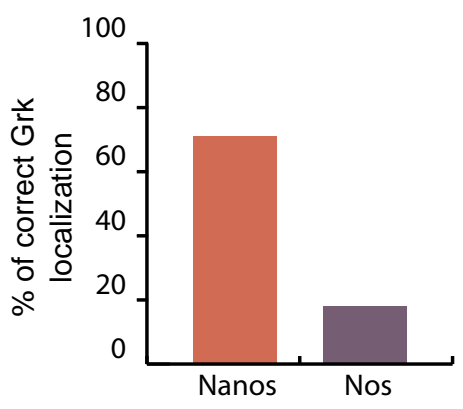

E

Su(Hw)::eGFP; su(Hw) $)^{v / e 04061}$

$\mathbf{F}$

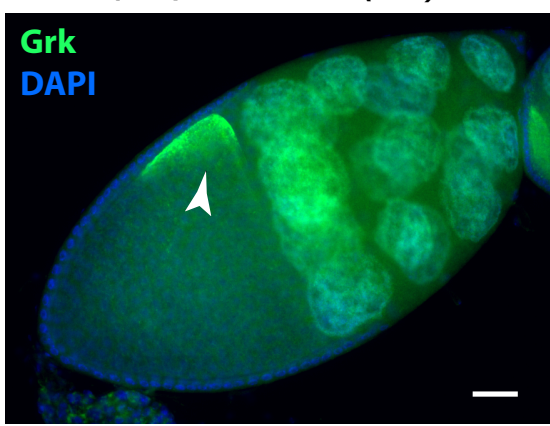

Su(Hw)::eGFP; su(Hw) $)^{v / 004061}$
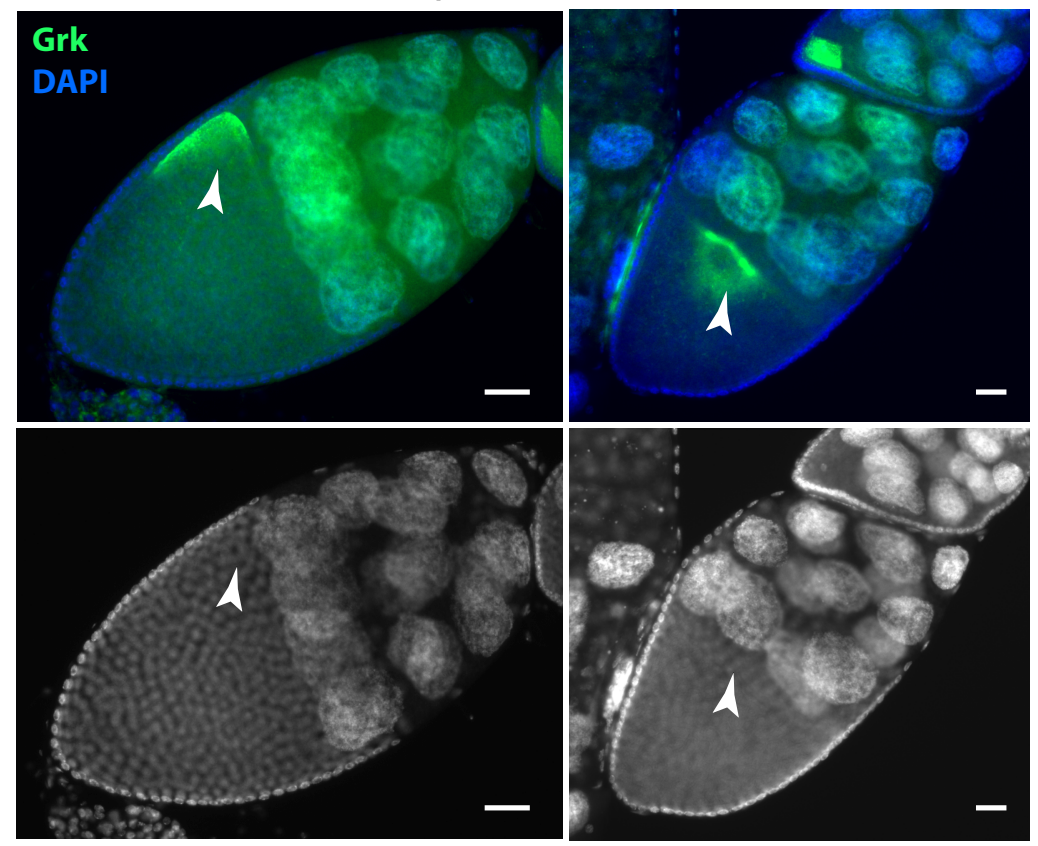

Figure 7 Hsu et al. 
bioRxiv preprint doi: https://doi.org/10.1101/551002; this version posted February 15,2019 . The copyright holder for this preprint (which was not certified by peer review) is the author/funder, who has granted bioRxiv a license to display the preprint in perpetuity. It is made available under aCC-BY-NC-ND 4.0 International license.

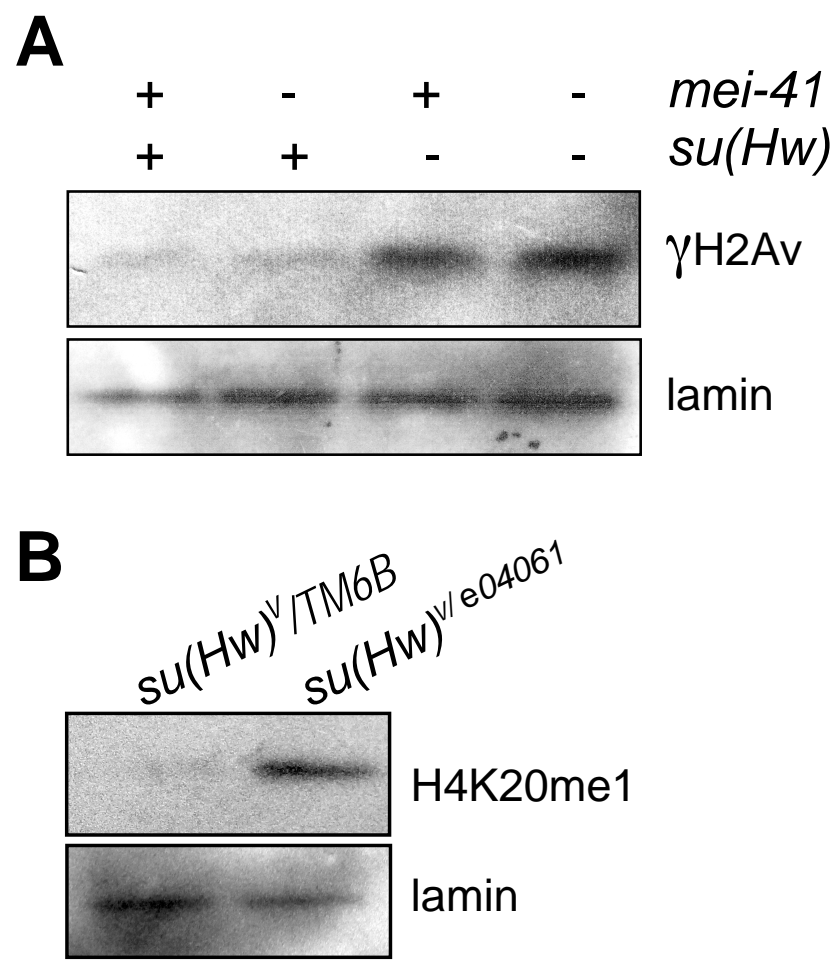

Figure 8 Hsu et al. 
bioRxiv preprint doi: https://doi.org/10.1101/551002; this version posted February 15,2019 . The copyright holder for this preprint (which was not certified by peer review) is the author/funder, who has granted bioRxiv a license to display the preprint in perpetuity. It is made available A under aCC-BY-NC-ND 4.0 International license.
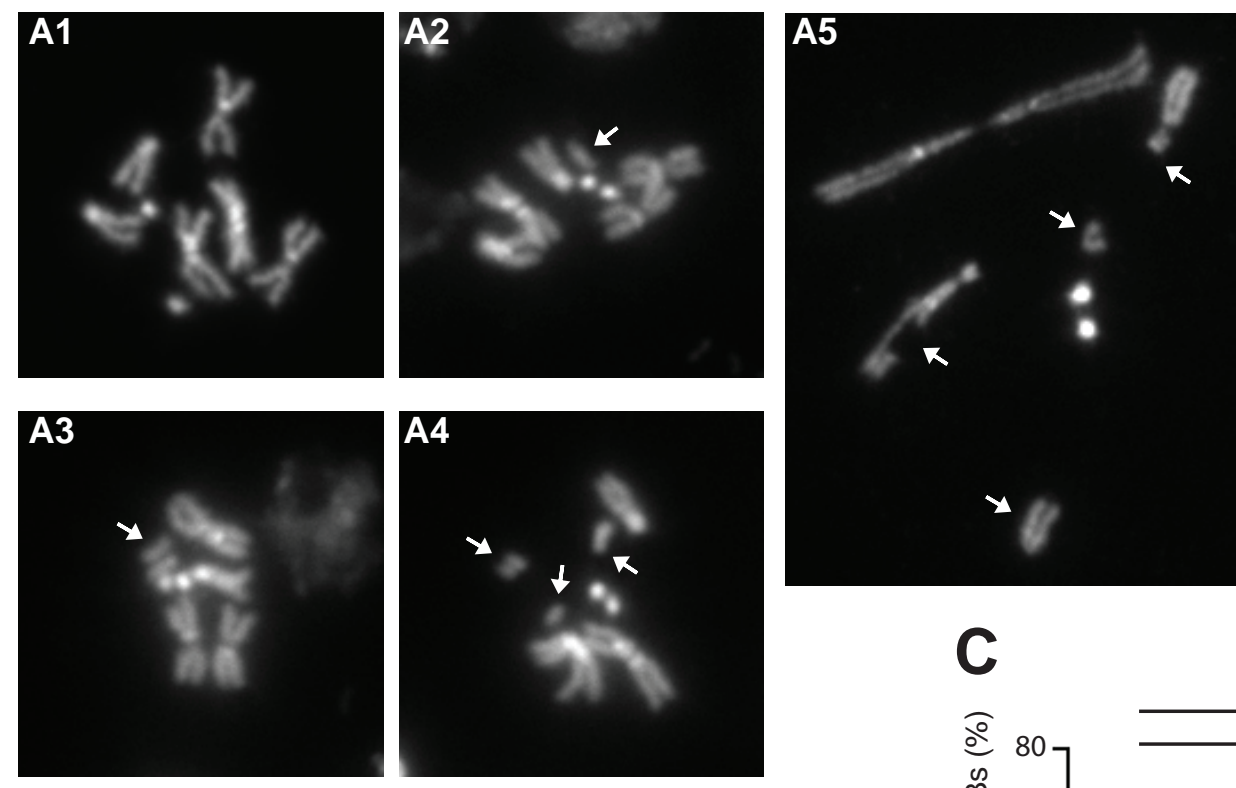

\section{B}

\begin{tabular}{|c|c|c|c|}
\hline Genotype & $\begin{array}{c}\text { Fraction of } \\
\text { cells with CABs }\end{array}$ & $\begin{array}{c}\text { \# of } \\
\text { cells }\end{array}$ & $\begin{array}{c}\text { \# of } \\
\text { brains }\end{array}$ \\
\hline OR & $0.7 \%$ & 467 & 7 \\
su $(H w)^{e 04061 / T M 6 B}$ & $1.5 \%$ & 325 & 6 \\
su $(H w)^{e 04061}$ & $11.9 \%$ & 796 & 21 \\
su $(H w)^{v / e 04061}$ & $8.2 \%$ & 402 & 8 \\
\hline
\end{tabular}
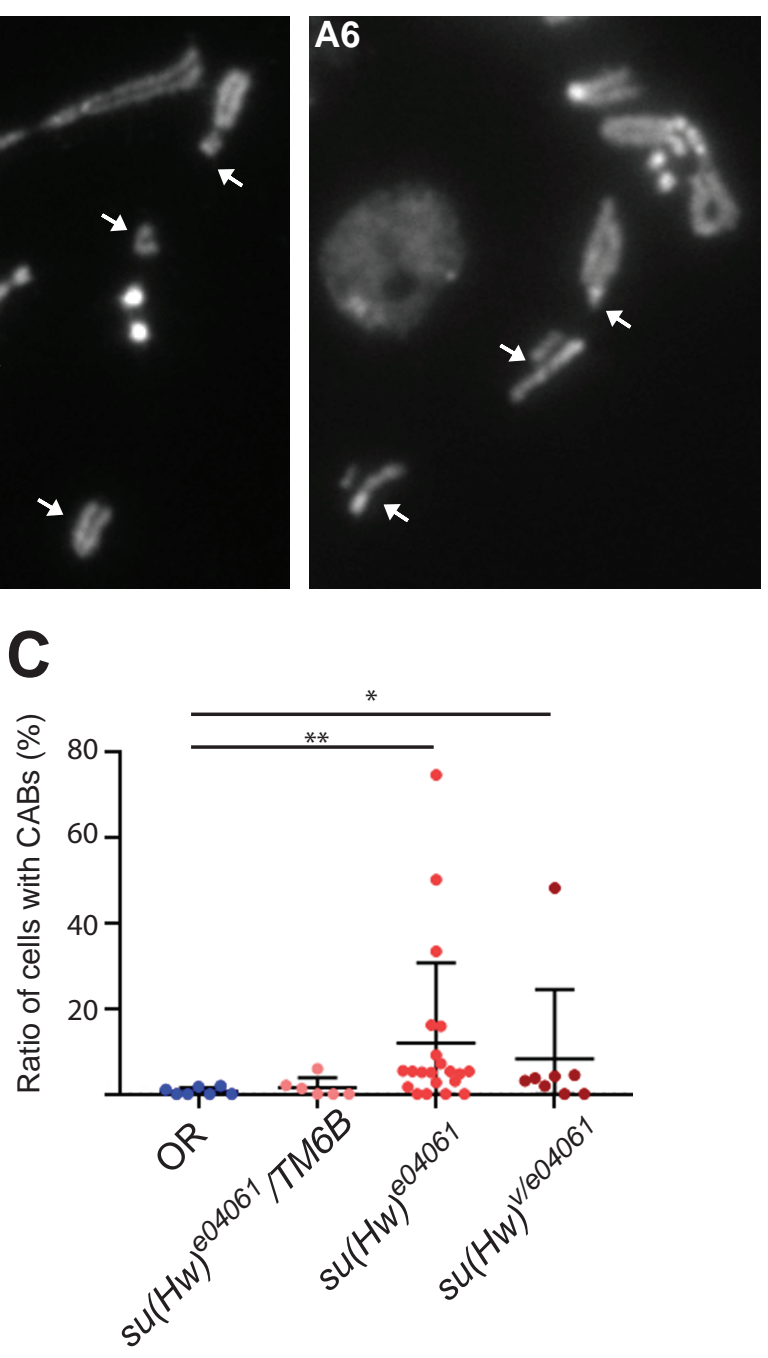

Figure 9 Hsu et al. 
bioRxiv preprint doi: https://doi.org/10.1101/551002; this version posted February 15,2019 . The copyright holder for this preprint (which was not certified by peer review) is the author/funder, who has granted bioRxiv a license to display the preprint in perpetuity. It is made available under aCC-BY-NC-ND 4.0 International license.

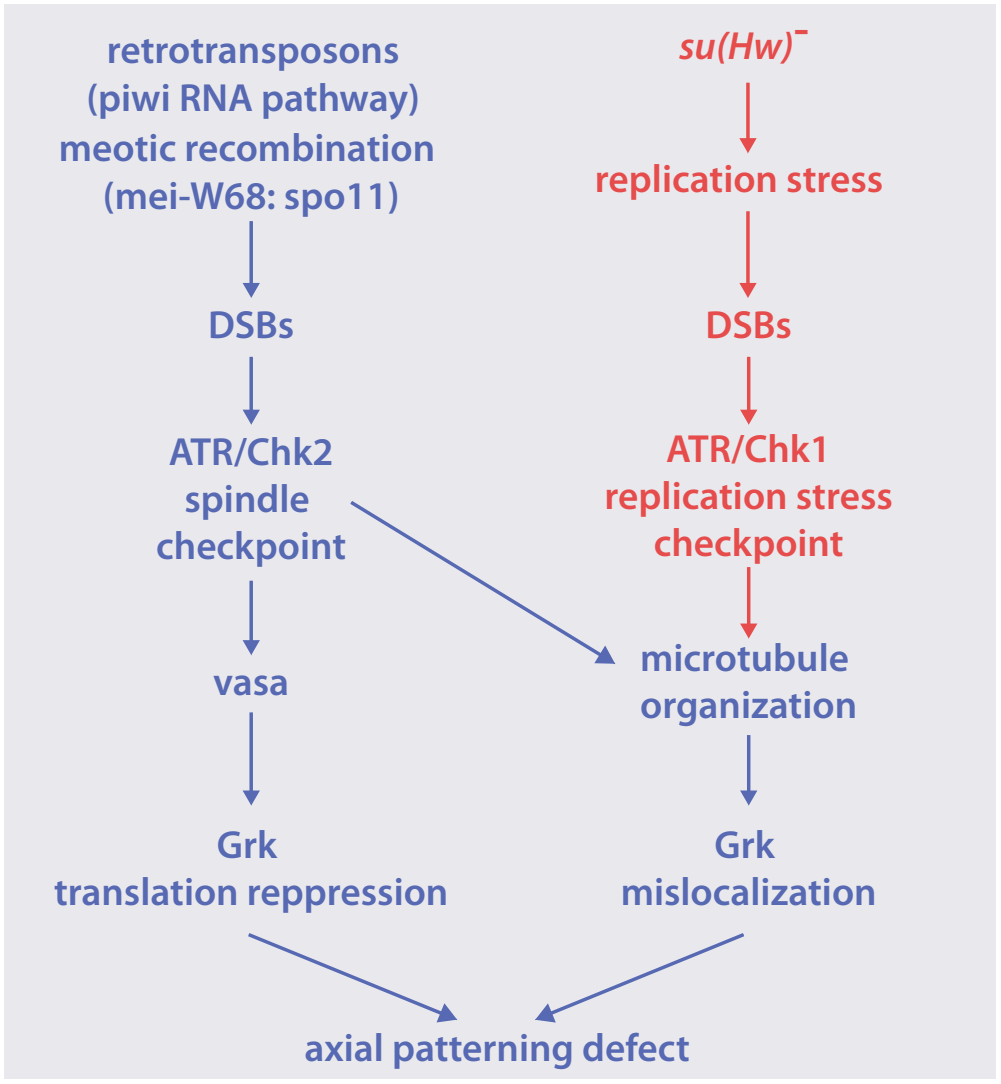

Figure 10 Hsu et al. 